\title{
Spectral sky models for advanced daylight simulations
}

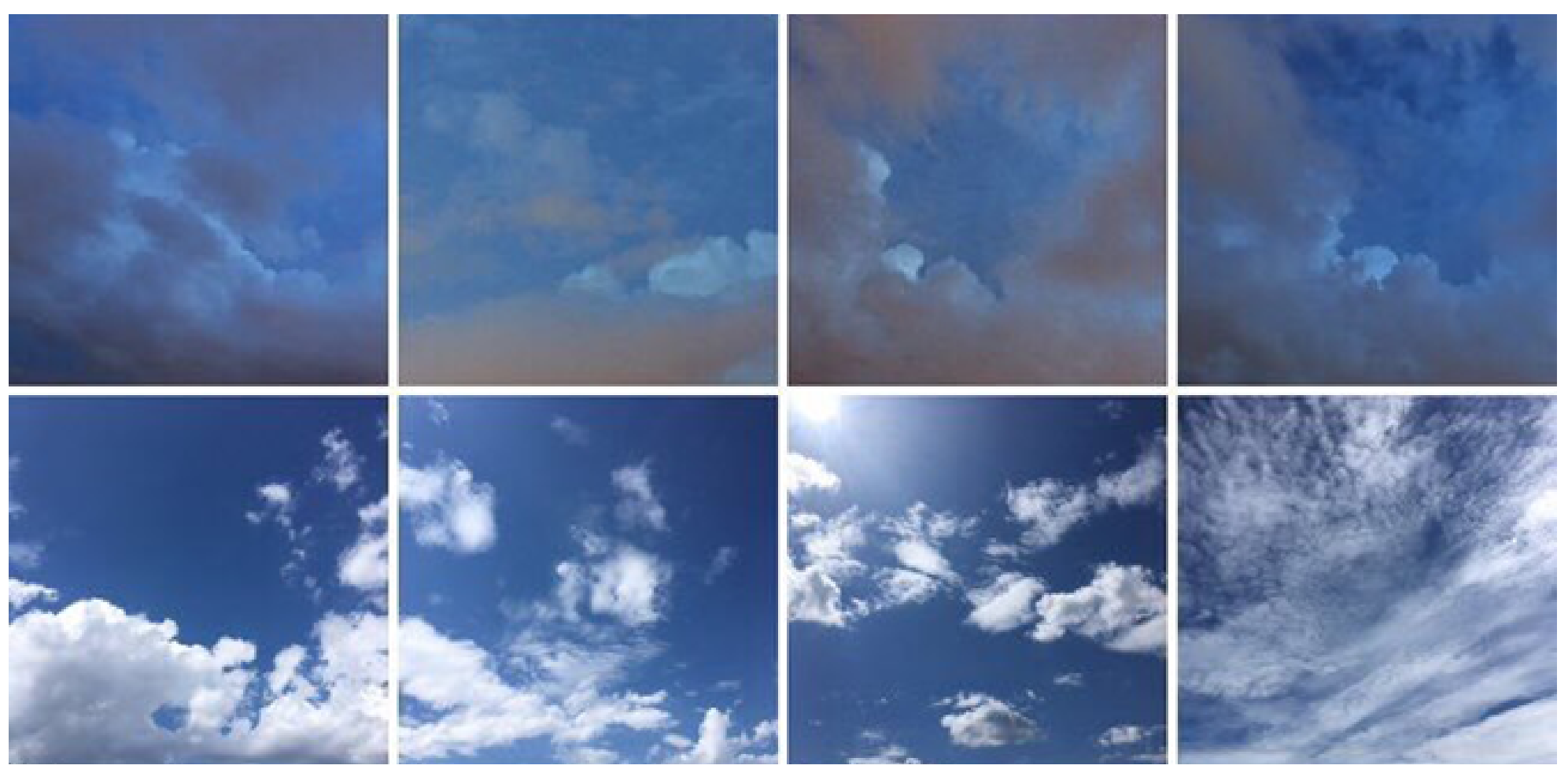

IEA SHC Task 61 / EBC Annex 77: Integrated Solutions for Daylighting and Electric Lighting 


\section{Solar Heating and Cooling Technology Collaboration Programme (IEA SHC)}

The Solar Heating and Cooling Technology Collaboration Programme was founded in 1977 as one of the first multilateral technology initiatives ("Implementing Agreements") of the International Energy Agency.

Our mission is "Through multi-disciplinary international collaborative research and knowledge exchange, as well as market and policy recommendations, the IEA SHC will work to increase the deployment rate of solar heating and cooling systems by breaking down the technical and nontechnical barriers."

IEA SHC members carry out cooperative research, development, demonstrations, and exchanges of information through Tasks (projects) on solar heating and cooling components and systems and their application to advance the deployment and research and development activities in the field of solar heating and cooling.

Our focus areas, with the associated Tasks in parenthesis, include:

- Solar Space Heating and Water Heating (Tasks 14, 19, 26, 44, 54)

- Solar Cooling (Tasks 25, 38, 48, 53, 65)

- Solar Heat for Industrial and Agricultural Processes (Tasks 29, 33, 49, 62, 64)

- Solar District Heating (Tasks 7, 45, 55)

- Solar Buildings/Architecture/Urban Planning (Tasks 8, 11, 12, 13, 20, 22, 23, 28, 37, 40, 41, $47,51,52,56,59,63,66)$

- Solar Thermal \& PV (Tasks 16, 35, 60)

- Daylighting/Lighting (Tasks 21, 31, 50, 61)

- Materials/Components for Solar Heating and Cooling (Tasks 2, 3, 6, 10, 18, 27, 39)

- Standards, Certification, and Test Methods (Tasks 14, 24, 34, 43, 57)

- Resource Assessment (Tasks 1, 4, 5, 9, 17, 36, 46)

- Storage of Solar Heat (Tasks 7, 32, 42, 58, 67)

In addition to our Task work, other activities of the IEA SHC include our:

$>$ SHC Solar Academy

$>$ Solar Heat Worldwide, annual statics report

$>\mathrm{SHC}$ International Conference

\section{Our members}

Australia

Austria

Belgium

Canada

CCREEE

China

Denmark

EACREEE

ECREEE

European Commission
European Copper Institute

France

Germany

International Solar Energy Society

Italy

Netherlands

Norway

Portugal

RCREEE

SACREEE
SICREEE

Slovakia

South Africa

Spain

Sweden

Switzerland

Turkey

United Kingdom

For more information on the IEA SHC work, including many free publications, please visit www.iea-shc.org. 


\section{Spectral sky models for advanced daylight simulations}

\section{A Technical Report of \\ IEA SHC Task 61 / EBC Annex 77 Subtask C3}

Editor: Aicha Diakite-Kortlever

Authors: Aicha Diakite-Kortlever, Priji Balakrishnan, Stanislav Darula, David Geisler-Moroder, J. Alstan Jakubiec, Martine Knoop, Tao Luo, Gunther Seckmeyer, Mario Tobar, Taoning Wang, Gregory J. Ward, Jan Wienold

\section{1-06-30}

T61.C.3 - A Technical Report of Subtask C DOI: 10.18777/ieashc-task61-2021-0005

The contents of this report do not necessarily reflect the viewpoints or policies of the International Energy Agency (IEA) or its member countries, the IEA Solar Heating and Cooling Technology Collaboration Programme (SHC TCP) members or the participating researchers. 
AUTHORS (in alphabetical order)

Priji BALAKRISHNAN

Architecture and Sustainable Design

Singapore University of Technology and

Design

8 Somapah Road

Singapore 487372

prijibalakrishnan@gmail.com

Stanislav DARULA

Dúbravská cesta 9

84503 Bratislava 45

Slovak Republic

Stanislav.Darula@savba.sk

Aicha DIAKITE-KORTLEVER

Technische Universität Berlin

FG Lichttechnik

Einsteinufer 19

10587 Berlin

Germany

a.diakite@hotmail.com

David GEISLER-MORODER

Bartenbach $\mathrm{GmbH}$

Rinner Strasse 14

6071 Aldrans

Austria

david.geisler-moroder@bartenbach.com

\section{J. Alstan JAKUBIEC}

University of Toronto

Daniels Faculty of Architecture, Landscape and Design / The School of the Environment

1 Spadina Crescent

Toronto, ON M5S 2J5

Canada

alstan.jakubiec@daniels.utoronto.ca

\section{Martine KNOOP}

Technische Universität Berlin

FG Lichttechnik

Einsteinufer 19

10587 Berlin

Germany

martine.knoop@tu-berlin.de

\section{Tao LUO}

China Academy of Building Research

No.30 Beisanhuan East Road

Beijing

China

luotao@chinaibee.com
Gunther SECKMEYER

Leibniz University of Hannover

Institute of Meteorology and Climatology

Herrenhaeuser Str.2

30419 Hannover

Germany

seckmeyer@muk.uni-hannover.de

\section{Mario TOBAR}

Institute of Meteorology and Climatology Herrenhaeuser Str.2

30419 Hannover

Germany

Taoning WANG

Lawrence Berkeley National Laboratory

1 Cyclotron Road

Berkeley California 94720

United States of America

taoningwang@lbl.gov

\section{Greg WARD}

Anyhere Software

950 Creston Rd.

Berkeley, California 94708

United States of America

gregoryiward@gmail.com

\author{
Jan WIENOLD \\ EPFL ENAC IA LIPID \\ LE 1111 (Bâtiment LE) \\ Station 18 \\ $\mathrm{CH}-1015$ Lausanne \\ jan.wienold@epfl.ch
}




\section{KEYWORDS}

Spectral sky models; daylight simulations; spectral measurements; spectral radiance; spectral irradiance; material properties; daylighting

\section{ACKNOWLEDGEMENTS}

The authors thank their respective funding agencies for supporting their work:

- The work of Technische Universität Berlin was supported by the VELUX Stiftung (grant number 1087)

- The work at Bartenbach GmbH was supported by the Federal Ministry for Climate Action, Environment, Energy, Mobility, Innovation and Technology (BMK) through the IEA Research Cooperation program managed by the Austrian Research Promotion Agency FFG (project 864136).

- The work at LBNL and Anyhere Software was supported by the Assistant Secretary for Energy Efficiency and Renewable Energy, Building Technologies Office of the U.S. Department of Energy under Contract No. DE-AC02-05CH11231, and by the California Energy Commission under the Electric Program Investment Charge (EPIC) Program, Solicitation Number: PON-13301, entitled "Developing A Portfolio of Advanced Efficiency Solutions: Technologies and Approaches for More Affordable and Comfortable Buildings". 


\section{PREFACE}

Lighting accounts for approximately $15 \%$ of the global electric energy consumption and $5 \%$ of greenhouse gas emissions. Growing economies, higher user demands for quality lighting and rebound effects as a result of low priced and more versatile electric lighting continuously still lead to an absolute increase of lighting energy consumption. More light is used, often less consciously.

Especially the electric lighting market but as well the façade, daylighting und building automation sectors have seen significant technological developments in the past decade. However, these sectors still act mainly independent of each other, leaving out big potentials lying in a better technology and market integration. This integration is on the one hand beneficial to providing better user-centred lighting of indoor spaces. On the other hand, it can contribute significantly to the reduction of worldwide electricity consumptions and C02-emissions, which is in line with several different governmental energy efficiency and sustainability targets.

IEA SHC Task 61 / EBC Annex 77 "Integrated Solutions for Daylighting and Electric Lighting - From component to system efficiency" therefore pursues the goal to support and foster the better integration of electric lighting and daylighting systems including lighting controls with a main focus on the nonresidential sector. This includes the following activities:

- Review relation between user perspective (needs/acceptance) and energy in the emerging age of "smart and connected lighting" for a relevant repertory of buildings.

- Consolidate findings in use cases and "personas" reflecting the behaviour of typical users.

- Based on a review of specifications concerning lighting quality, non-visual effects as well as ease of design, installation and use, provision of recommendations for energy regulations and building performance certificates.

- Assess and increase robustness of integrated daylight and electric lighting approaches technically, ecologically, and economically.

- Demonstrate and verify or reject concepts in lab studies and real use cases based on performance validation protocols.

- Develop integral photometric, user comfort and energy rating models (spectral, hourly) as prenormative work linked to relevant bodies: CIE, CEN, ISO. Initialize standardization.

- Provide decision and design guidelines incorporating virtual reality sessions. Integrate approaches into widespread lighting design software.

- Combine competencies: Bring companies from electric lighting and façade together in workshops and specific projects. Hereby support allocation of added value of integrated solutions in the market.

To achieve this goal, the work plan of IEA SHC Task 61 / EBC Annex 77 is organized according to the following four main subtasks, which are interconnected by a joint working group:

- Subtask A:

- Subtask B:

- Subtask C:

- Subtask D:

- Joint Working Group:
User perspective and requirements Integration and optimization of daylight and electric lighting Design support for practitioners (Tools, Standards, Guidelines) Lab and field study performance tracking

Evaluation tool \& VR Decision Guide 


\section{EXECUTIVE SUMMARY}

This technical report deals with the current state of the art in the field of spectral measurements and models of daylight. The presented document is a result of joint work conducted by members of the IEA SHC Task 61 / EBC Annex 77, Subtask C3. It provides an overview of:

(i) daylight sites conducting spectral (radiance, irradiance) measurements

(ii) spectral sky models

(iii) simulation software supporting spectral calculations

The first part of the report focuses on the spatially resolved (radiance) and global (irradiance) spectral measurements. The two approaches at different locations are presented, and a comparison of the two approaches is given. Next, the currently existing spectral sky models are summarized, subdivided into data-driven and analytical models. The section "Review of spectral sky models" includes additionally a proposal to simplify the models for practical application. Section 4 addresses material properties, comprising glazing and opaque materials. Further, the document discusses three simulation platforms LARK, ALFA, and RADIANCE that support spectral calculations. The last part of the reports offers design guidelines comprised of: spectral daylight potential diagrams (SDPD) displaying the orientation dependent spectral characteristics of daylight on the façade, and urban aesthetics studying the aesthetics of changing sky conditions for urban environments of various materiality. The document closes with related ongoing activities tackling the topic of spectral characterization of daylight to unfold the potential of daylight in lighting design and research. 


\section{Contents}

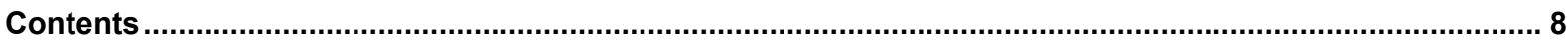

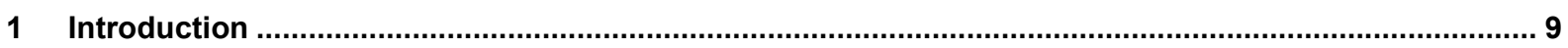

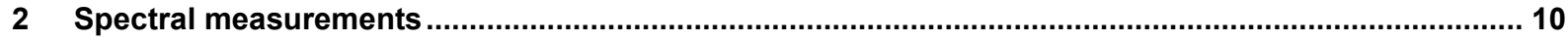

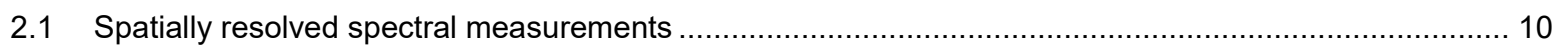

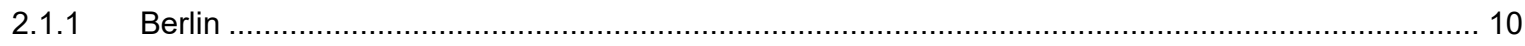

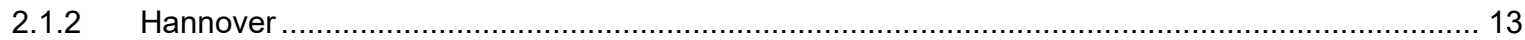

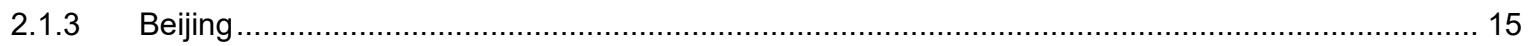

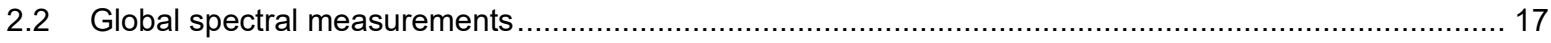

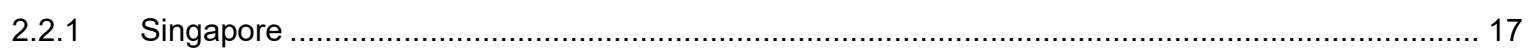

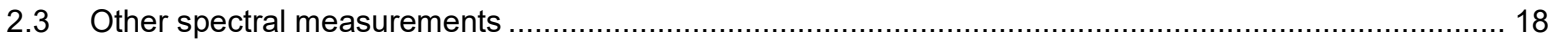

2.4 Comparison of Global and Spatially Resolved Spectral Measurements.............................................. 19

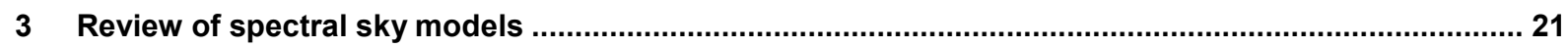

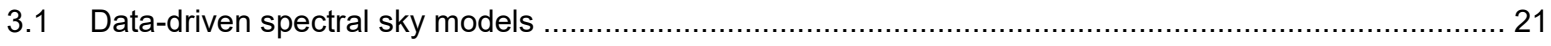

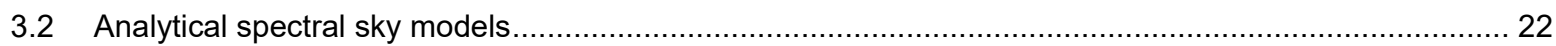

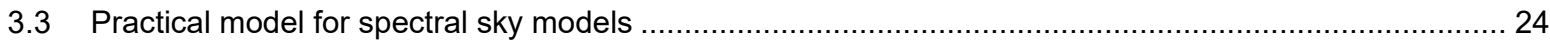

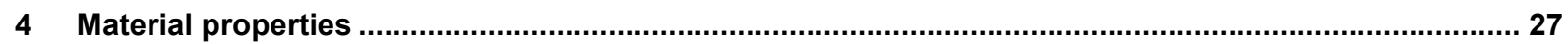

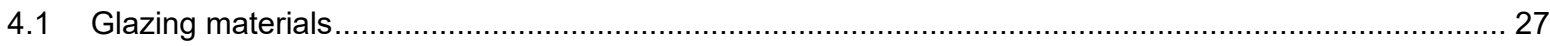

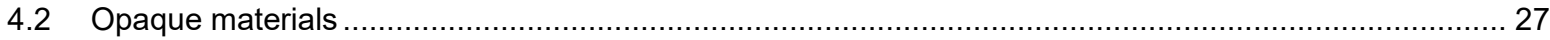

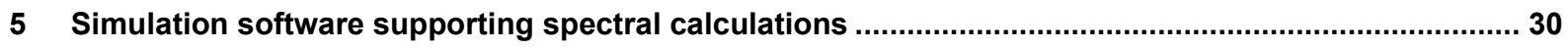

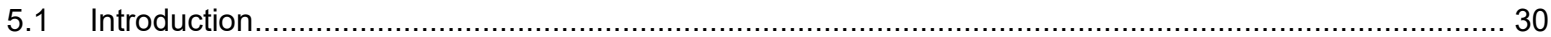

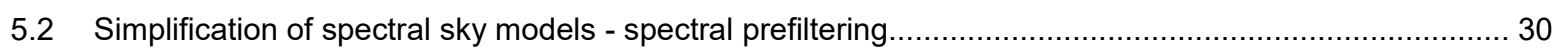

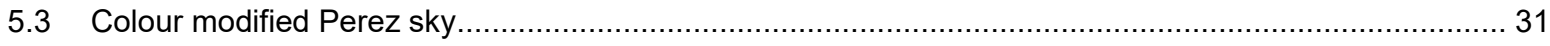

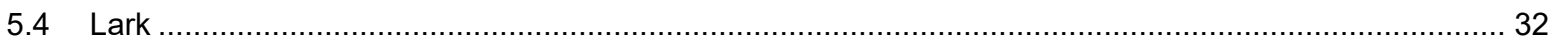

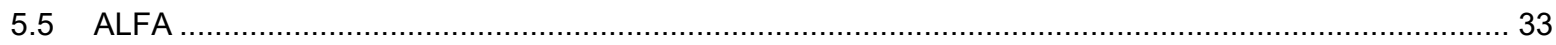

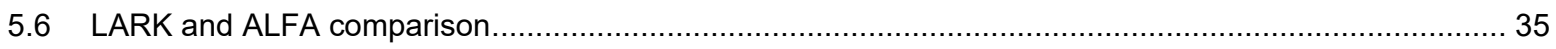

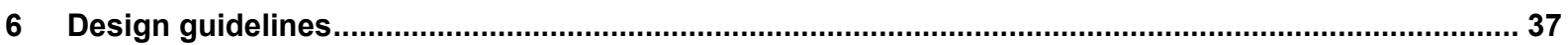

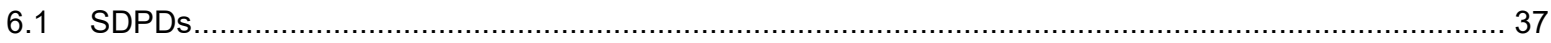

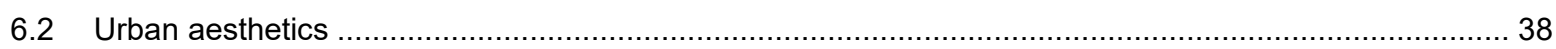

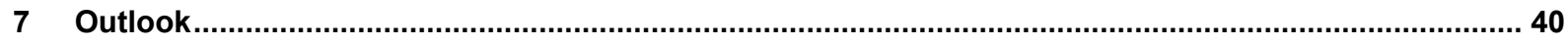

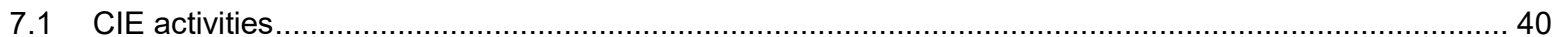

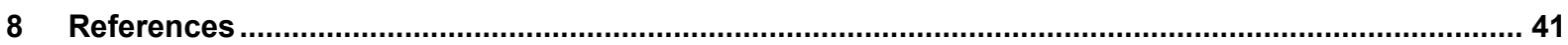

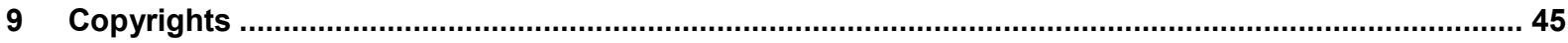




\section{Introduction}

Daylight is seen as the primary light source as well as the template for indoor lighting designed to enhance human well-being through non-visual effects of this light. To quantify the potential of daylight and the energy efficiency of non-visual effective lighting, the inclusion of spectral characteristics of daylight in the design process is of specific interest.

This document includes:

- an overview of measurement sites collecting colorimetric daylight information,

- a review of existing spectral models and a proposal to simplify these,

- a description of daylight simulation methods that include spectral calculations, and

- design guidelines.

An overview of spectral resources included in this document, and a reference to detailed information to it, can be found in Table 1.

Table 1: Overview of spectral resources (spectral measurements and spectral sky models)

\begin{tabular}{|l|l|l|l|}
\hline & $\begin{array}{l}\text { Measurements } \\
\text { Section 2 }\end{array}$ & $\begin{array}{l}\text { Models (data-driven) } \\
\text { Section 3.1 }\end{array}$ & $\begin{array}{l}\text { Models (analytical) } \\
\text { Section 3.2 }\end{array}$ \\
\hline $\begin{array}{l}\text { Spatially } \\
\text { resolved } \\
\text { measurements }\end{array}$ & $\begin{array}{l}\text { Beijing, Berlin, Hannover, } \\
\text { Granada }\end{array}$ & Bratislava, Berlin & LibRADtran \\
\hline $\begin{array}{l}\text { Global } \\
\text { measurements }\end{array}$ & $\begin{array}{l}\text { Singapore, Almeria, } \\
\text { Eugene, Lindenberg, } \\
\text { Granada, Cherry Springs } \\
\text { State Park, Pennsylvania }\end{array}$ & & \\
\hline
\end{tabular}




\section{Spectral measurements}

In general, one can distinguish between two different approaches to conduct spectral daylight measurements:

1. spatially resolved spectral radiance measurements from areas (patches) of the sky, and

2. global, hemispheric, spectral irradiance measurements, typically including both skylight and combinations of skylight and sunlight.

The usage of these measurements in simulation tools is addressed in section 5.3 "Colour modified Perez sky" for spatially resolved measurements, and in section 5.4 "Lark" for global spectral measurements. The application of the colorimetric daylight information in design guidelines is described in section 6 "Design guidelines".

\subsection{Spatially resolved spectral measurements}

Spatially resolved spectral power distribution measurements of daylight have been performed for years in Hannover, Germany (Riechelmann et al. 2013, Tohsing et al. 2014), Beijing, China (Luo et al. 2015) and Berlin, Germany (Knoop 2014). These measurement sites are described below in more detail. Similar spatially resolved spectral measurements were carried out in Bratislava, Slovakia (Komar et al. 2013, Dubnicka et al. 2014) and Kyoto, Japan (Uetani 2014).

\subsubsection{Berlin}

by Aicha Diakite-Kortlever and Dr. Martine Knoop, Technische Universität Berlin, Germany

Since 2014, ground-based spectral measurements have been carried out at the daylight measuring site of the Technische Universität Berlin (Figure 1) located at $52^{\circ} 31^{\prime}$ $\mathrm{N}, 13^{\circ} 20^{\prime} \mathrm{E}$, with an elevation of the location (urban areas) between $31 \mathrm{~m}$ to $70 \mathrm{~m}$ Above Mean Sea Level (AMSL) (Amt für Statistik Berlin - Brandenburg 2018) and a mounting altitude of the measuring devices of $50 \mathrm{~m}$. The spatially and temporally resolved spectral skylight data are acquired without direct sunlight using a highprecision custom-made sky scanner by Czibula \& Grundmann, equipped with an array spectroradiometer (Zeiss Multi-Channel-Spectrometer MCS CCD with a Hamamatsu back-thinned CCD). The employed measuring system meets the increased requirements for spectral coverage, spatial resolution, and temporal variations that a light source as dynamic as daylight presents. Due to the variability in prevailing sky conditions spectral irradiance or radiance measurements must be performed in short periods of time. It is therefore recommended to adopt the time frame for luminance measurements of daylight as proposed by the CIE (1994), which is set at an upper limit of 2.5 minutes. The scanner is designed to collect spectral data of all predefined sky sections distributed over the entire sky-dome in one measuring series. The subdivision of the sky hemisphere follows the Tregenza distribution proposed in Tregenza (1987) and adopted by the CIE (1994), which results in 145 sky patches. A complete series of measurement is completed within approximately one minute, with a longer duration for twilight. Every second minute, beginning at nautical dawn and ending at nautical dusk (solar altitude at $6^{\circ}$ to $12^{\circ}$ below the horizon in the morning and in the evening), the spectral sky scanner measures the spectral irradiance between $280 \mathrm{~nm}$ and 
$980 \mathrm{~nm}$ from the 145 sky patches within an aperture angle of $10^{\circ}$ using a step size of approximately $0,8 \mathrm{~nm}$. This has resulted in over 30 million daylight spectra, and the measuring process is still ongoing. It is one of the few measuring sites worldwide that collect this kind of data. A detailed characterization of the spectral sky scanner used is discussed in Knoop et al. (2017).

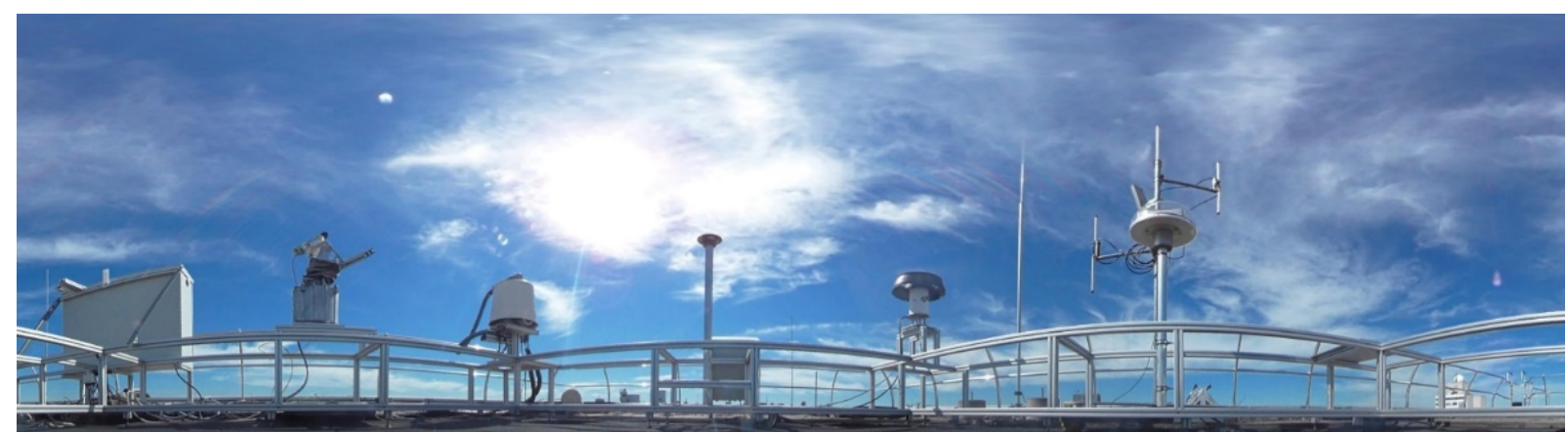

Figure 1: Spectral sky scanner at daylight measuring site at the Technische Universität Berlin 


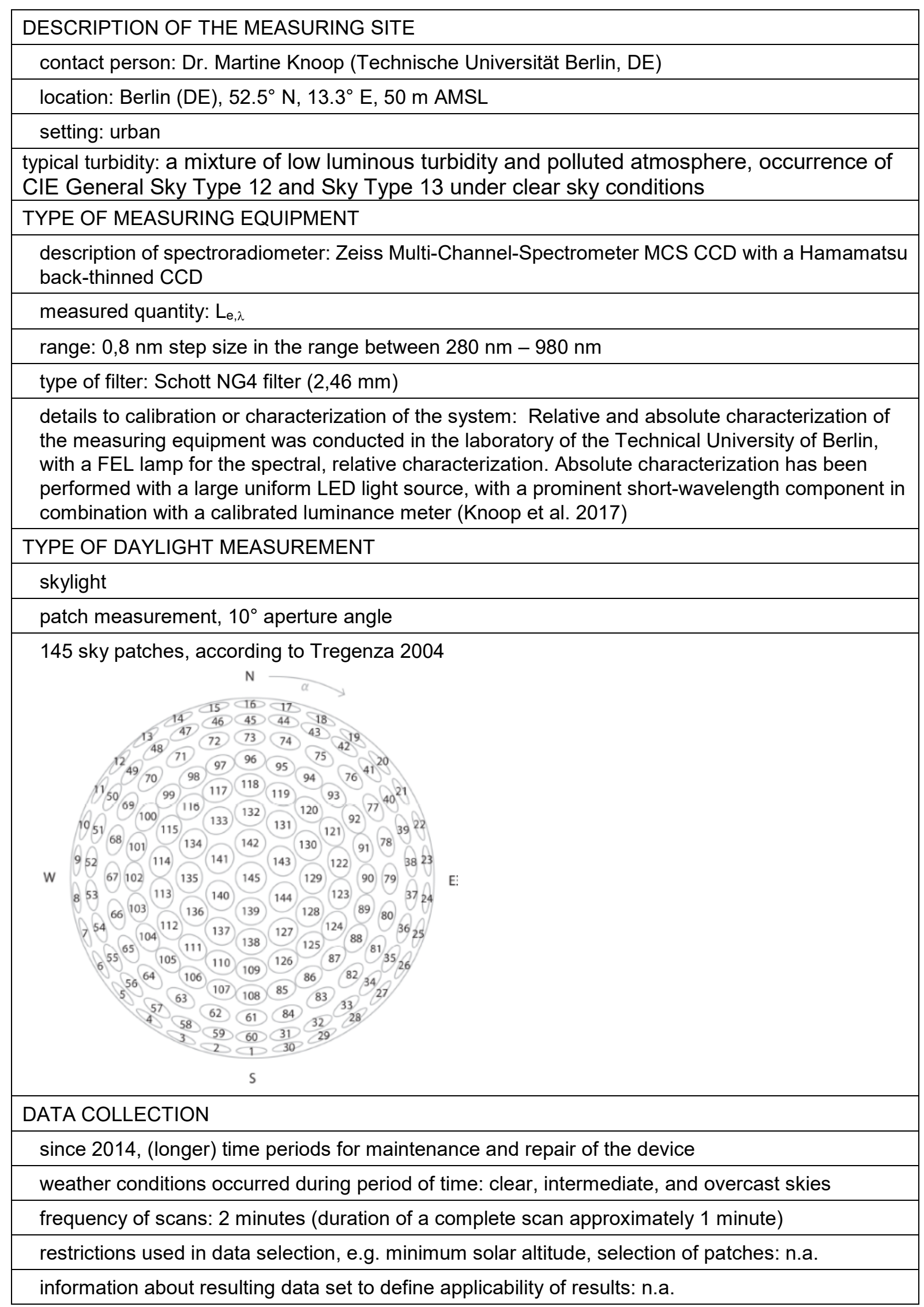

Contact: martine.knoop@tu-berlin.de 


\subsubsection{Hannover}

by Prof. Dr. Gunther Seckmeyer and Mario Tobar, Leibniz Universität Hannover, Germany

The variations in the spectral radiance distribution are measured in the range $280 \mathrm{~nm}$ to $1700 \mathrm{~nm}$ using a new type of multi-directional spectroradiometer called AMUDIS (Advanced MultiDlrectional Spectroradiometer, Figure 2) (Seckmeyer et al. 2018, p.119), based on the prototype MUDIS (Riechelmann, Schrempf, and Seckmeyer 2013). The new device allows measurements with a high spectral and temporal resolution. AMUDIS is composed of 3 monochromators and 3 cameras for each one of the spectral ranges (UV, VIS y NIR). A multi-directional entrance optics with multiple apertures conducts radiation from different sections of the sky through optical fibers to the spectroradiometers. Each of the apertures holds 3 mono-fibers (one for each spectral range). At the other end of the optical fiber bundle are the 145 fibers vertically aligned in a metallic cylinder. The spectroradiometer then divides the light into its spatial and spectral components. Due to its design for simultaneous measurement of spectral radiance, the influence of rapidly changing aerosols and clouds may be studied by this instrument.

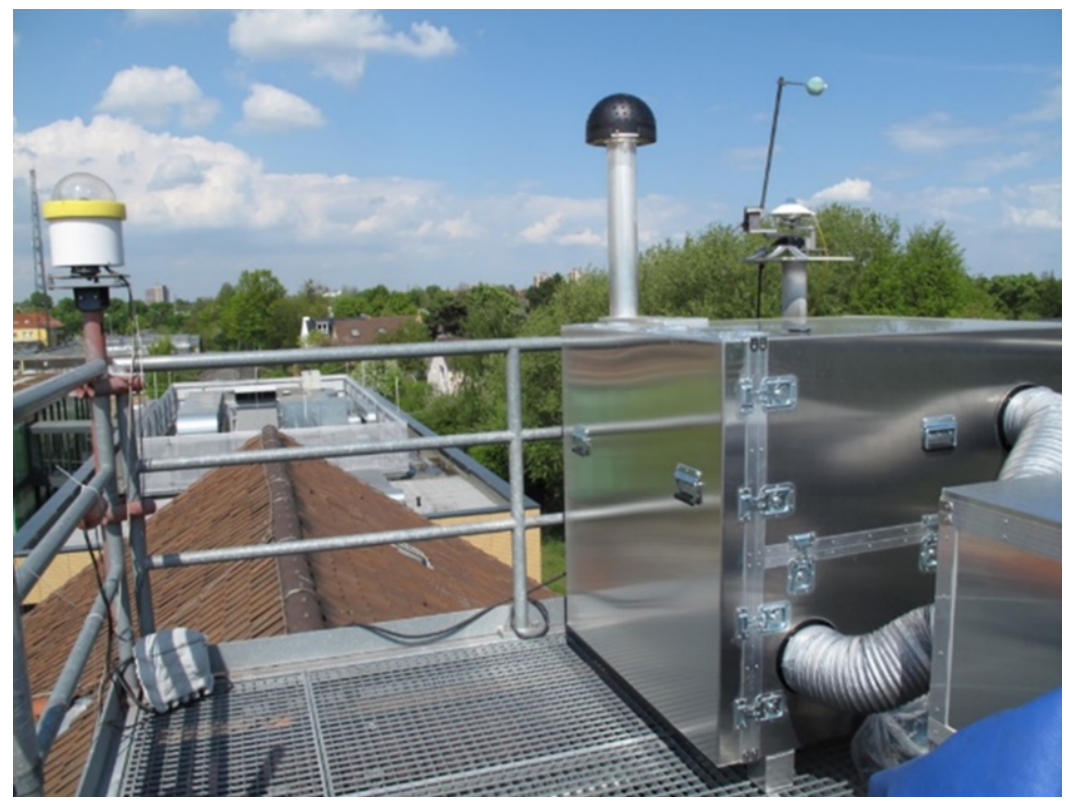

Figure 2: AMUDIS at the measuring site of Leibniz Universität Hannover 


\begin{tabular}{|c|}
\hline DESCRIPTION OF THE MEASURING SITE \\
\hline contact person: Prof. Dr. Gunther Seckmeyer \\
\hline location: $52.39^{\circ} \mathrm{N}$ and $9.7^{\circ} \mathrm{E}, 65 \mathrm{~m}$ AMSL \\
\hline setting: urban \\
\hline typical turbidity (or CIE General Standard Clear Sky Type with highest occurrence): - \\
\hline TYPE OF MEASURING EQUIPMENT \\
\hline $\begin{array}{l}\text { description of spectroradiometer: Princeton instruments SpectraPro } 500 \mathrm{i}, 500 \mathrm{~mm} \text { focal length. It } \\
\text { features an astigmatism-corrected optical system. Diffraction grating: UV } 110 \mathrm{~g} / \mathrm{mm} \text {, VIS } 50 \mathrm{~g} / \mathrm{mm} \text {, } \\
\text { NIR } 30 \mathrm{~g} / \mathrm{mm}\end{array}$ \\
\hline measured quantity: $L_{e 日}$ \\
\hline range: UV $280 \mathrm{~nm}-400 \mathrm{~nm}$, VIS $380-900 \mathrm{~nm}$, NIR $890-1700 \mathrm{~nm}$, step size $0.5 \mathrm{~nm}$ \\
\hline type of filter: No filter \\
\hline $\begin{array}{l}\text { details to calibration or characterization of the system: Calibrated on laboratory using integrating } \\
\text { spheres of } 100 \mathrm{~cm} \text { (UK100) (absolute calibration) and } 40 \mathrm{~cm} \text { (UK40) (relative calibration) } \\
\text { diameter. The integrating spheres have } 3 \times 100 \text { watts halogen lamps positioned under the equator } \\
\text { of the spheres. The internal radiance of the UK100 was measured by using a pre-calibrated } \\
\text { NDACC reference double-monochromator spectroradiometer. The absolute calibration was } \\
\text { carried out at the beginning of the measurement campaign. }\end{array}$ \\
\hline TYPE OF DAYLIGHT MEASUREMENT \\
\hline skylight \\
\hline patch measurement, field of view between $5^{\circ}(\mathrm{NIR})$ up to $18^{\circ}(\mathrm{UV})$ depending on the wavelength \\
\hline 145 patches distributed as the figure below \\
\hline DATA COLLECTION \\
\hline 08.08.2019-18.10.2019 (Dataset not yet available) \\
\hline weather conditions occurred during period of time: - \\
\hline frequency of scans: $0.166 \mathrm{~min}$ (10 seconds) \\
\hline restrictions used in data selection: - \\
\hline $\begin{array}{l}\text { information about resulting data set to define applicability of results: number of scans: } \sim 300.000 \\
\text { and SPDs }\end{array}$ \\
\hline
\end{tabular}

Contact: seckmeyer@muk.uni-hannover.de 


\subsubsection{Beijing}

by Dr. Tao Luo, China Academy of Building Research, China

Since January 2012, luminance and spectral distribution measurements of daylight are carried out with a spectral sky scanner in Beijing. Beijing has a typical temperate monsoon climate, the average annual sunshine duration is from $2000 \mathrm{~h}$ to $2800 \mathrm{~h}$. The station is located on the roof of the main building of the China Academy of Building Research (CABR). The sky scanner, which employs a spectrum test method, was designed and manufactured by CABR and the Beijing Aoptek Scientific Co., Ltd (Figure 3). The spectral measurements, using a maximum step size of $1 \mathrm{~nm}$ between $200 \mathrm{~nm}$ and $1100 \mathrm{~nm}$, are performed with a USB4000 fiber optic spectrometer. A halogen lamp, placed on a $180^{\circ}$ rotating bracket, is used for daily self-calibration, using correction software to fit the measured spectrum to CIE standard illuminant $\mathrm{A}$. In order to reduce the effect of ambient temperature, dark background noise is measured before each test. The scanner's aperture angle is $11^{\circ}$, realized by a shutter inside the lens cone. It can complete a 145-point measurement of the sky dome according to Tregenza (1987) in three minutes, scans are performed every 30 minutes. To ensure the accuracy and reliability of the zenith luminance test, the zenith luminance is measured three times in each scan. If the difference in the obtained results was less than $10 \%$, the average of the three measurements is taken as the zenith luminance; otherwise, the scan is repeated. After finishing each test, the aiming angle is reset to the south. The angular errors of the horizontal and vertical directions are less than $0.5^{\circ}$. Luminances are obtained by numerical integration, and the maximum error is less than $1,2 \%$ (range from $1000 \mathrm{~cd} / \mathrm{m}^{2}$ to $20000 \mathrm{~cd} / \mathrm{m}^{2}$ ).

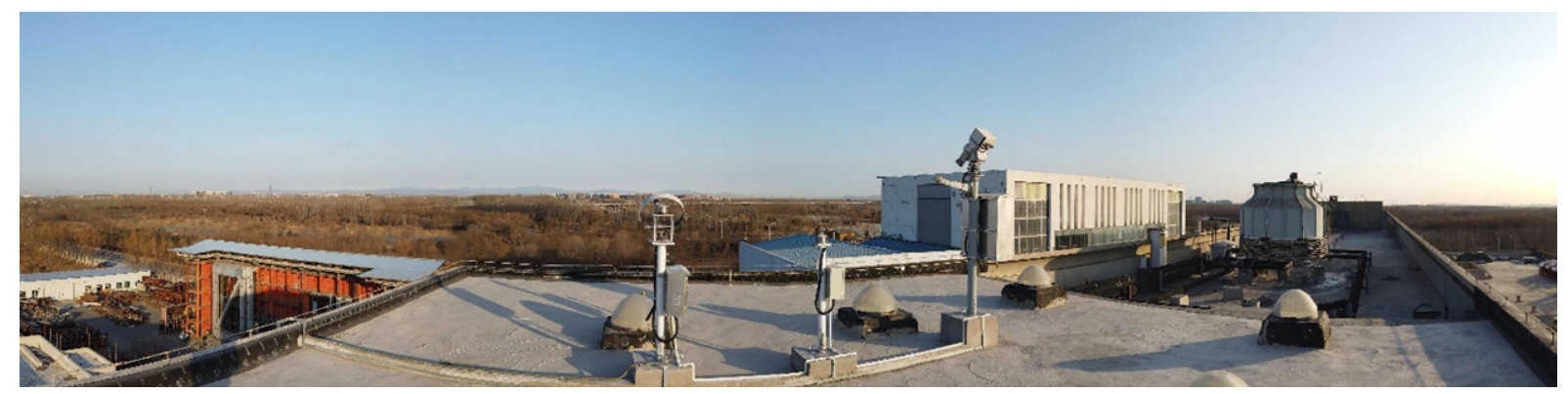

Figure 3: Spectral sky scanner at measuring site of China Academy of Building Research 


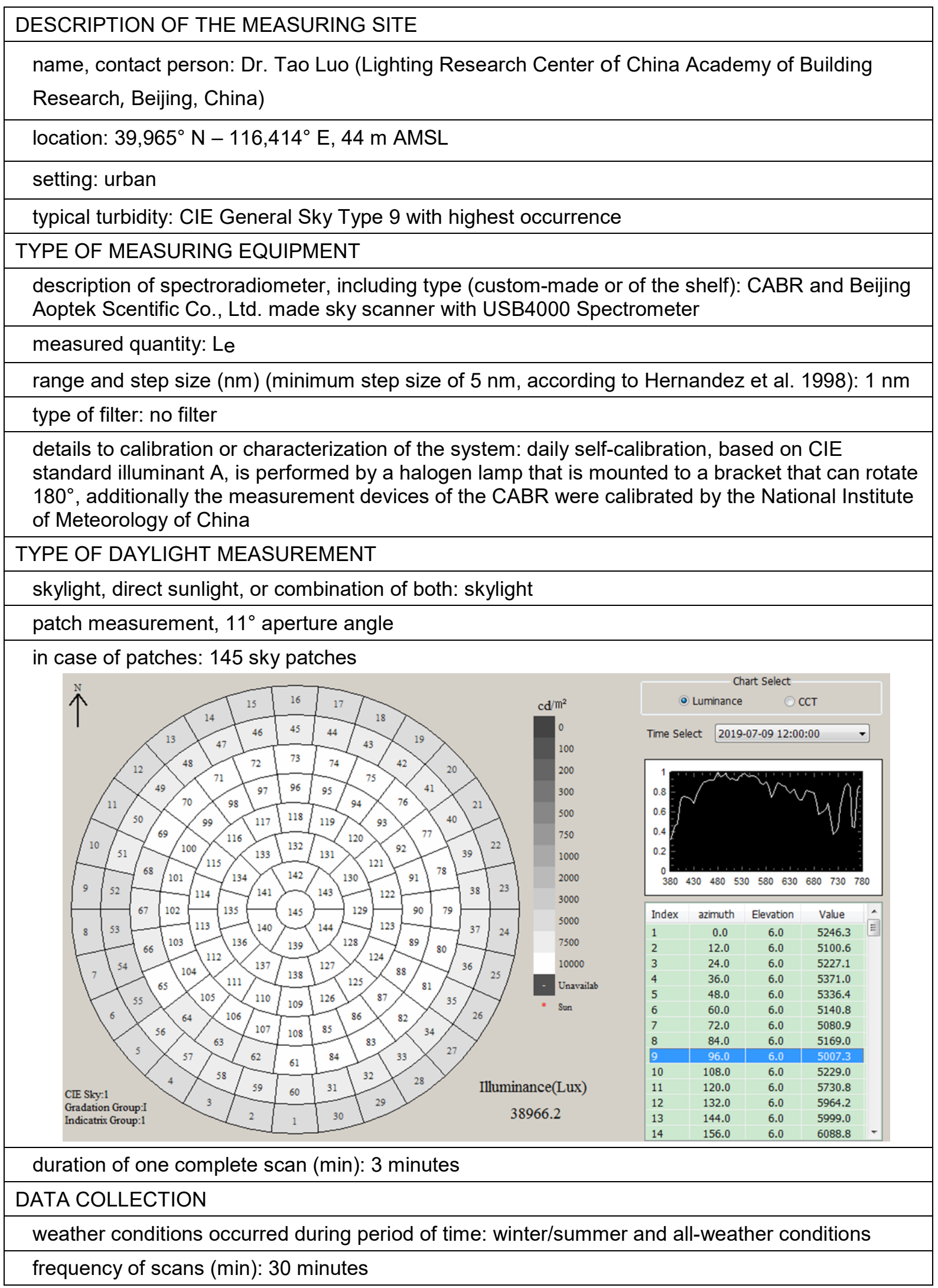

Contact: luotao@chinaibee.com 


\subsection{Global spectral measurements}

\subsubsection{Singapore}

\section{by Dr. J. Alstan Jakubiec, University of Toronto, Canada}

Observations of the global spectral irradiance $\left(\mathrm{W} / \mathrm{m}^{2}-\mathrm{nm}\right)$, visual color, and photopic luminance $\left(\mathrm{cd} / \mathrm{m}^{2}\right)$ of skies were recorded in Singapore $\left(1.35^{\circ} \mathrm{N}, 103.82^{\circ} \mathrm{E}\right)$ during November - December 2016 and February - August 2018 as part of the PhD research of Priji Balakrishnan (2019). The broad purpose of these measurements was to compare spectral renderings using tools such as Lark (Inanici et al. 2015) and ALFA (Solemma 2017) to in-situ measurements. Vertical measures of urban contexts as well as horizontal measurements of largely unobstructed skies were collected; however, due to the urban measurement conditions, some horizontal obstruction is present. This subsection is concerned only with the horizontal measurements of sky spectral irradiance.

A Konica Minolta CL-500A illuminance spectrophotometer was mounted on a fixed tripod with integrated level and pointed vertically towards the sky before taking a measurement. Simultaneously a Canon EOS 5D Mark III camera with an equisolid projection fisheye lens (Canon EF 8-15mm F/4L USM) was used to capture a high dynamic range (HDR) photograph of the sky with North being oriented Y-up in the resulting image. Since the measurements were paired, each spectral irradiance measure has associated perceptual color and luminance information. Figure 4 illustrates a typical measurement setup on site.

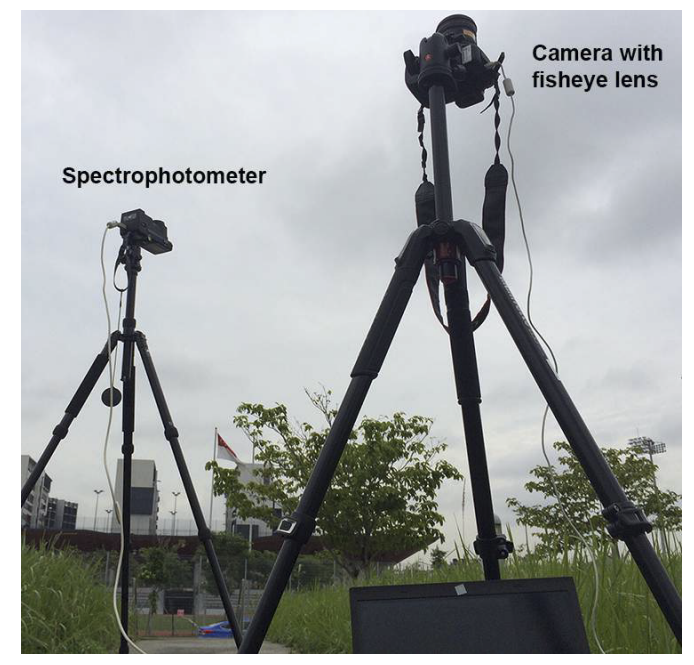

Figure 4: Image of in-situ measurements being collected in Singapore

The global spectral irradiance measurements (in W. $\mathrm{m}^{-2} \cdot \mathrm{nm}^{-1}$ ) are measured in $1 \mathrm{~nm}$ incremental steps from $360 \mathrm{~nm}$ to $780 \mathrm{~nm}$ - ultraviolet and infrared data are not captured. The CL-500A sensor also includes associated data such as CCT (K) and global photopic illuminance (Ix). HDR photography is captured using the methods documented by Jakubiec et al. (2016a, 2016b) without neutral density filters or overflow correction. This means that the solar disc and circumsolar region are not accurately measured, but diffuse sections of the sky should be largely accurate.

Forty-four measurements were collected during clear sky conditions, intermediate sky conditions, overcast sky conditions, sunrise, and sunset. Figure 5 compares an 
overcast, intermediate, and clear sky from the measurements. The global spectral irradiance is plotted normalized to the peak of each measure.

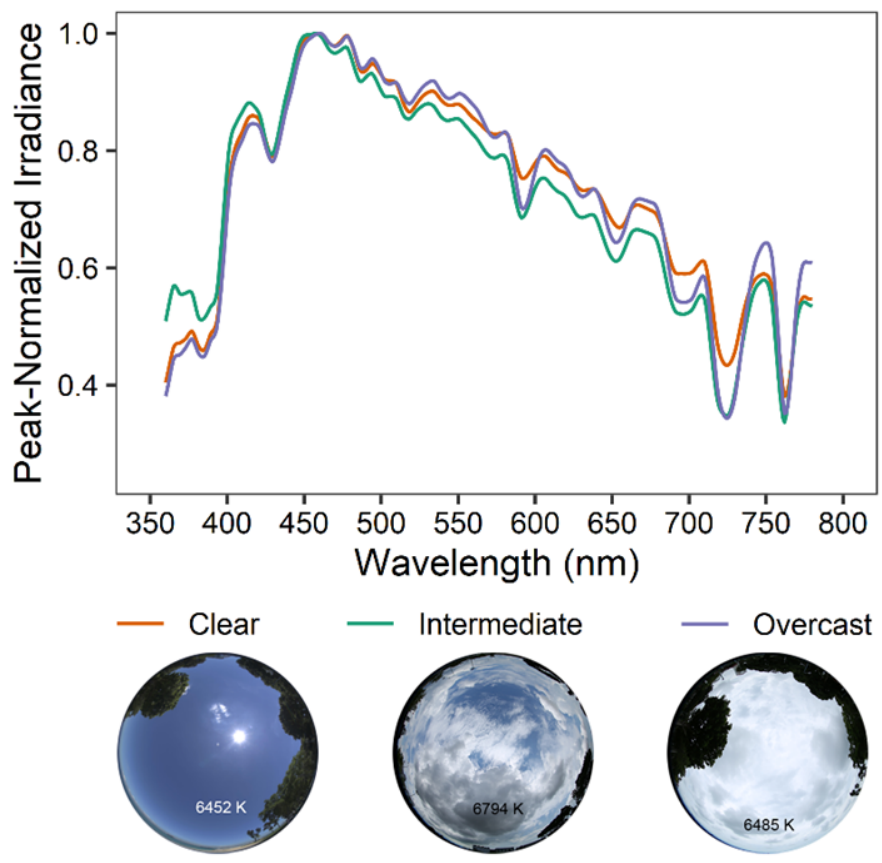

Figure 5: Comparison of three spectral sky measurements from the Singapore dataset

The data is available online at https://github.com/prijibalakrishnan/equatorialskies

\subsection{Other spectral measurements}

by Dr. Martine Knoop, Technische Universität Berlin, Germany

Various researchers and institutes collect or collected spectral daylight and skylight measurements. Included in the list below are those institutes that might share spectral data for research purposes.

- Deutsches Zentrum für Luft- und Raumfahrt (DLR), Institut für Solarforschung, Plataforma Solar de Almería (https://www.dlr.de/sf/en/desktopdefault.aspx/tabid-10224/17488_read-44933/)

- Almería, Spain (ongoing)

- University of Oregon, Solar Radiation Monitoring Laboratory

(http://solardat.uoregon.edu/SelectSpectral.html) for

$\circ$ Eugene, Oregon, USA (2015 - 2019), and

- Lindenberg, Tauche, Germany (2014 - 2019)

- University of Granada

(Hernández-Andrés et al. 2001a, Hernández-Andrés et al. 2001b)

- Granada, Spain (February 1996 to February 1998, and February to August 1998)

- University of Pennsylvania

(Spitschan et al. 2016)

- Cherry Springs State Park, Pennsylvania, USA (July 2014)

- Philadelphia, Pennsylvania, USA (July 2014) 


\title{
2.4 Comparison of Global and Spatially Resolved Spectral Measurements
}

\author{
by Dr. Martine Knoop, Technische Universität Berlin, Germany
}

A daylight locus reflects the chromaticities of CIE daylight illuminants in a chromaticity diagram (http://eilv.cie.co.at/term/283, Figure 6). CIE states that "Seasonal and geographical variations in the spectral power distribution of daylight occur" (CIE 2018b, p. 13), therefore the results of one measuring site are reflected in local daylight locus.

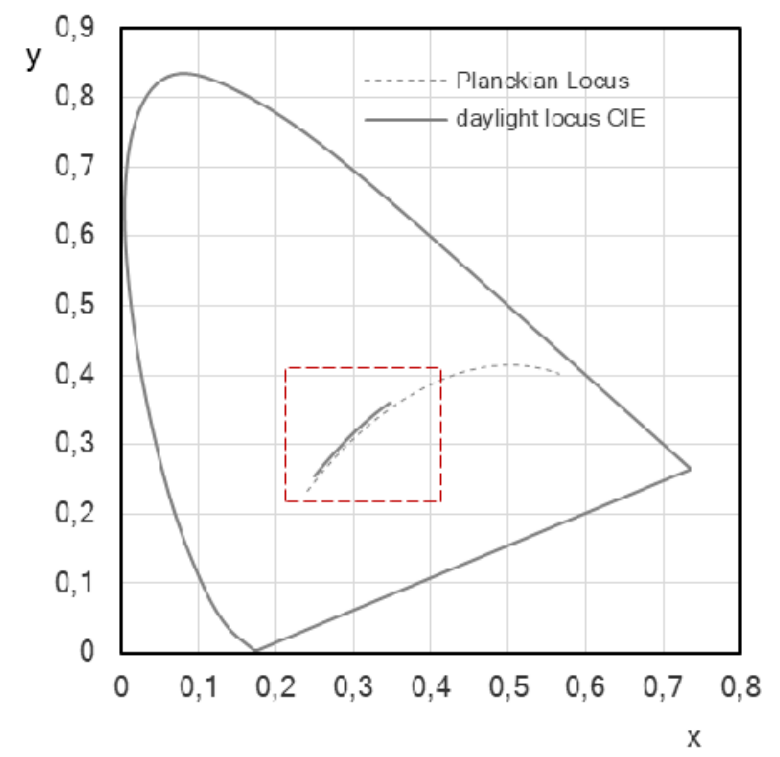

Figure 6: CIE x,y chromaticity diagram with the Planckian Locus and daylight locus red dotted square for reference to Figure 7

Hernández-Andrés et al. proposed a local daylight locus for global, hemispheric, spectral irradiance, including both skylight and combinations of skylight and sunlight (2001b), another local daylight locus for spectral radiance, derived from $3^{\circ}$ narrow fieldof-view, patch, measurements (2001a). Dubnicka et al. (2014) proposed two distinct local daylight loci as well. A smaller evaluation of patch and integral measurements conducted simultaneously by Knoop et al. (2019) could not confirm these findings. Therefore, further analysis of these kind of data at one location seems to be required to define whether global and spatially resolved measurements can be combined or need to be treated separately.

A first evaluation of global and spatially resolved measurements at various sites was conducted for the purpose of this document. (Onagan 2020) Measurements in Eugene (see Section 2.3), Berlin and Beijing were compared, for a selection of measuring periods. In this comparison, chromaticity coordinates of a large number of measurements (Table 2) are reflected in local daylight loci, again in reference to the daylight locus as defined in CIE 015:2018 (CIE 2018b).

Table 2: Overview of the Measurement Period and Number of Datasets of the Analyzed Daylight Data

\begin{tabular}{|l|c|c|}
\hline Measuring Site & Measurement Period (MM-YYYY) & Number of Datasets \\
\hline Eugene, OR, USA & $07-2015,01-2016,01-2018,07-2018$ & 57.435 \\
\hline Berlin, DE & $07-2015,01-2016,07-2016,01-2018$ & 176.293 \\
\hline Beijing, CN & $07-2015,01-2018,07-2018$ & 48.199 \\
\hline
\end{tabular}


The daylight loci for Eugene (rural location), Berlin and Beijing (urban locations) are (merely) overlapping (Figure 7 ), with a discrepancy in the range of chromaticity coordinates $(\mathrm{x}, \mathrm{y})$ only. The difference in chromaticity range is due to the difference in measurement set-up. The spectral measurements in Eugene are global spectral measurements, reflecting an integral, average, representation of the color of the sky. The spectral measurements in Berlin and Beijing are spatially resolved spectral measurements, capturing the colorimetric characteristics of specific regions of the sky which can vary largely. The local loci of Eugene and Berlin are somewhat closer to the Planckian locus than to the CIE daylight locus, except for the range with higher CCTs, where the Berlin daylight locus is 'above' both Planckian and CIE daylight locus. The Beijing locus is closer to the original $\mathrm{CIE}$ daylight locus. Further analysis of spectral daylight measurements is planned (Knoop et al. 2019, Section 7.1).
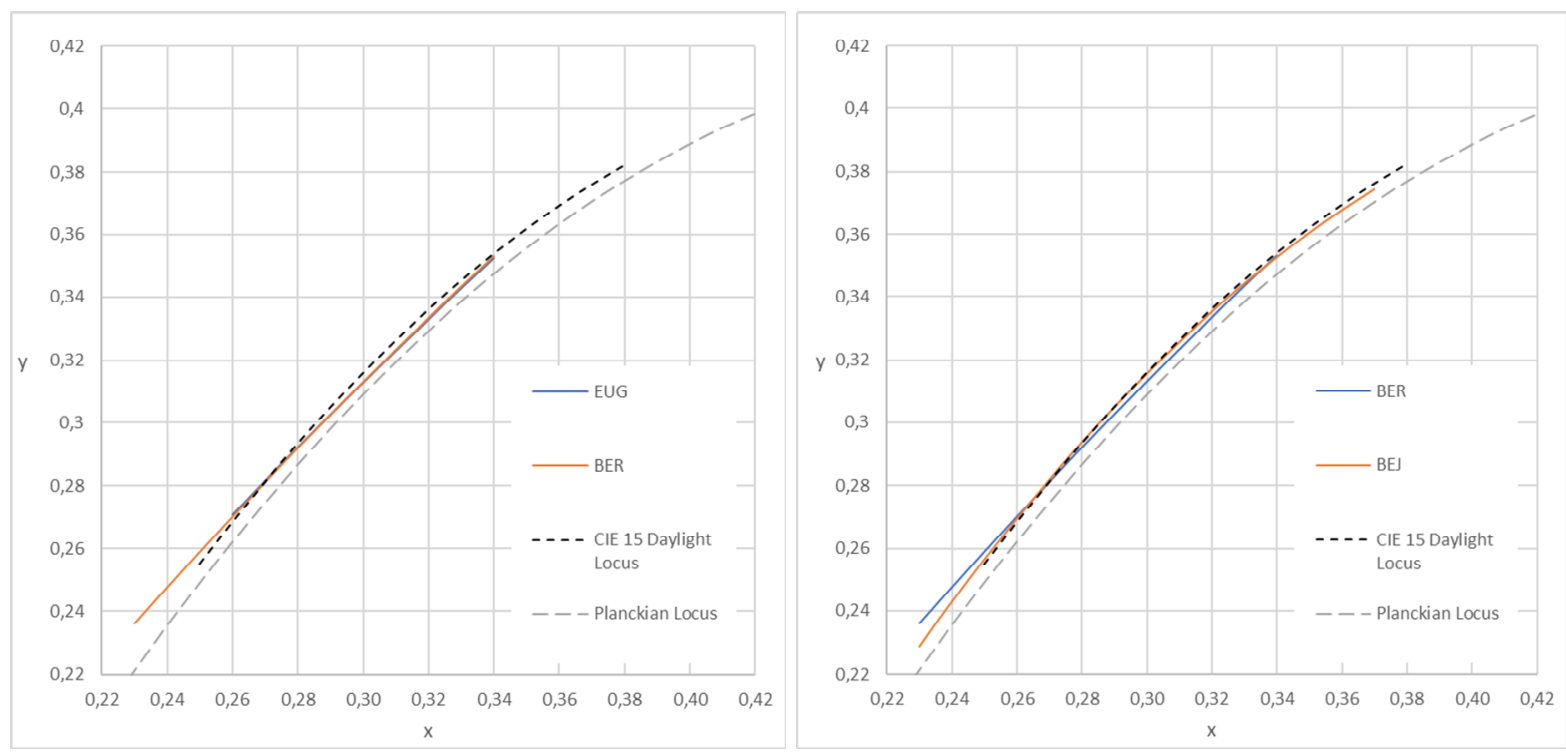

Figure 7: Examples of measurement points and local daylight loci in a section of the CIE x,y chromaticity diagram (see Figure 6) for the Eugene (rural, EUG) and Berlin (urban, BER) measurement sites (left) and for the urban measurement sites Beijing (BEJ) and Berlin (BER) (right) (Onagan 2020) 


\section{Review of spectral sky models}

Spectral sky models or measured sky data are required for the practical calculation of spectral irradiances. Sky models specifically are beneficial for predictive calculations as would be performed during a design process aimed at the nonvisual or colorspecific effects of light. This section gives an overview of existing data-driven spectral sky models (section 3.1) and analytical, ostensibly physics-based, spectral sky models (section 3.2). ALFA, a spectral simulation tool described in section 6.5 , also employs a physics-based sky model which is described briefly in that section.

\subsection{Data-driven spectral sky models}

\section{by Aicha Diakite-Kortlever, Technische Universität Berlin, Germany}

Spectral sky models describe the colour distribution of the skylight relating the CCT of a specific sky patch to its luminance. Based on spectral measurements Takagi et al. (1990), Chain et al. (1999a, 2004), and Rusnák (2014) have been able to express the correlation in empirical fittings of the CCT as a function of luminance (Figure 8). A review of these fittings is detailed in Diakite and Knoop (2019a).

Figure 8 (reproduced from Diakite and Knoop (2019a) with permission from the publisher): Current

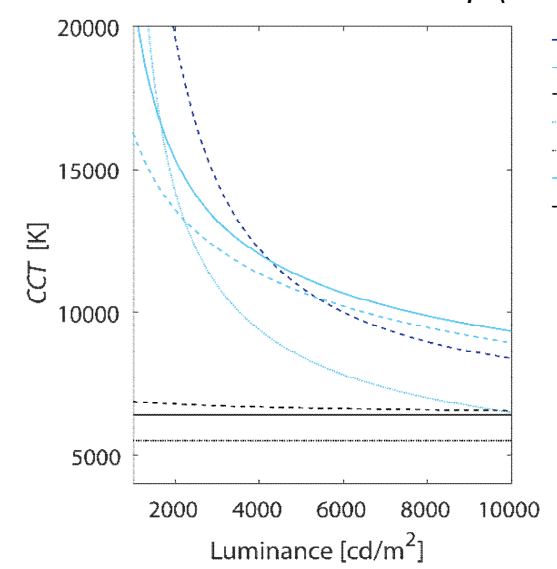

-.- Takagi etal 1990

Chain et al. 1999-1, clear sky

Chain et al. 1999-1, overcast sky

Chain 2004, LCF $=120$

Chain 2004, LCF $=0$

Rusnák 2014, CIE 12

...- Rusnák 2014, CIE 3

state-of-the-art, data-driven, spectral sky models based on the relationship between luminance and correlated colour temperature (CCT)

by: Takagi et al. (1990) (-.., dark blue), Chain et al. (1999a) (-, light blue/black);

Chain (2004) (..., light blue/black), and Rusnák (2014) (---, light blue/black)

Takagi et al. (1990) first translated the mathematical linkage between the luminance and CCT into an equation (1) in Table 3. Measurements underlying the fitting were collected in Japan (the exact location was not stated).

Chain et al. (1999a) confirmed the correlation between luminance and CCT for Vaulxen-Velin (France), and additionally found that the relation varies depending on weather conditions and, therefore, sky type. Based on observations from their spectral directional measurements Chain and colleagues (1999a) formulated major trends for the three sky categories: clear sky conditions, overcast sky conditions, and intermediate sky conditions. From these observations Chain et al. (1999a) then proposed two models, one for overcast and another for clear sky conditions. The fitting function for clear skies (equation (2) in Table 3) exhibited a logarithmic correlation between luminance and the reciprocal of CCT. Overcast skies were set to a fixed value of $6415 \mathrm{~K}$. Intermediate skies were not expressed in a general equation. Further 
improvement of the model (Chain et al. 1999b, Chain 2004) were achieved through the introduction of a new, sky type dependent parameter, the Luminance Colour Factor (LCF). LCF can be calculated from solar altitude $\gamma_{S}$ and sky clearness $\varepsilon$ (Perez et al. 1993). Chain (2004) first related the CCT distribution to a radiometric model drawing upon the All-Weather model (Perez et al. 1993) and suggested one single equation comprising all sky states (equation (4) in Table 3).

Rusnák (2014) transformed the expression used in Chain et al. (1999a) to equation (5) based on spatially resolved spectral measurement conducted in Bratislava (Slovakia). Rusnák (2014), however, related the CCT distribution with luminance distribution using the sky type classification of CIE Standard General Skies in accordance with the ISO / CIE Standard (CIE 2003), which encompasses 15 standardized luminance distributions for clear, overcast, and intermediate skies.

Table 3: Summary of existing spectral models based on the correlation between luminance of a sky patch and its CCT

\begin{tabular}{|l|c|c|}
\hline $\begin{array}{l}\text { Takagi et } \\
\text { al. (1990) }\end{array}$ & \multicolumn{3}{|c|}{$C C T=\frac{1,1985 \cdot 10^{8}}{\mathrm{~L}^{1,2}}+6500$} \\
\hline $\begin{array}{l}\text { Chain et al. } \\
(1999 a)\end{array}$ & $\begin{array}{l}\text { clear sky: } \\
C C T=\frac{10^{6}}{-132,1+59,77 \cdot \log _{10} L}\end{array}$ & overcast sky: \\
\hline $\begin{array}{l}\text { Chain } \\
(2004)\end{array}$ & $C C T=\frac{10^{6}}{181,35233+L C F^{*} \cdot\left(-4,22630+\log _{10} L\right)}$ \\
\hline $\begin{array}{l}\text { Rusnák } \\
(2014)\end{array}$ & $C C T=\frac{10^{6}}{p L^{q^{* *}}}$
\end{tabular}

where $L$ is the luminance at any point of the sky $\left[\mathrm{cd} \cdot \mathrm{m}^{-2}\right]$ and $C C T$ is the correlated colour temperature $[K]$.

* where LCF is the Luminance Colour Factor and is given by:

$\mathrm{LCF}=21.56308+\left(82.33165-0.77050 \cdot \gamma_{S}\right) \cdot\left(1.10439+\log _{10}(\varepsilon-0.9)\right)\left(\right.$ Chain 2004, p. 171), where $\gamma_{S}$ is solar altitude $\left[^{\circ}\right]$ and $\varepsilon$ is the sky clearness according to Perez et al. 1993.

${ }^{* *}$ where the coefficients $q$ and $p$ are the mean values of the empirical measurements per sky type tabulated in Rusnák (2014), p.81

Together, these studies prove a strong correlation between the luminance of a sky patch and its CCT depending on prevailing sky conditions. More recent studies in Berlin and Beijing (Knoop et al. 2015, Knoop et al. 2017) support these findings. For detailed review of the existing spectral sky models refer to Diakite and Knoop (2019a). A review of existing data-driven sky models, investigating which of the models performs best when validated against a large dataset of spatially, spectrally and temporally resolved measurements in the context of the NIF effectiveness of daylight is presented in Diakite-Kortlever and Knoop (2021).

\subsection{Analytical spectral sky models}

\section{by Dr. J. Alstan Jakubiec, University of Toronto, Canada}

Several analytical or theory-driven models exist for spatial and spectral distribution of the sky dome. While the physics of sky spectrum are reasonably well understood when the profile of atmospheric gases is known, these factors are often unknown and the 
physics are computationally expensive to solve. Nishita et al. $(1993,1996)$ produced two of the earliest models for realistic skies in the computer graphics field. Nishita et al. (1993) proposed an algorithm that could calculate optical length and sky light accounting for air molecules and aerosols in discretized, concentric layers. In 1996 the model was updated with the possibility of modeling anisotropic scattering and discreete cloud volumes within the atmosphere. Preetham et al. (1999) compiled a model meant to reduce the complexity of Nishita's previous models, and its input parameters were meant to be easily meausreable or estimateable. It is based on a least-squares fit to the Nishita et al. (1996) model and the data-driven Perez et al. (1993) all weather sky luminance model, and the only required parameter is beyond the solar position is the sky turibidity. O'Neil's (2005) model is essentially a simplification for computational speed of Nishita et al.'s 1993 model by replacing the transmittance integral with an analytic function; therefore, it lacks anisotropic atmospheric scattering. Haber et al. (2005) improved upon Nishita et al.'s (1996) model by using a sperical grid to store atmospheric layer data and by computing anisotropic scaterring in all directions, which was not done before. Haber also integrated the refractive index of atmospheric air as well as ozone absorption. Bruneton and Neyret's (2008) model uses a more discretized, parametric grid for atmospheric parametrs and are the first to include ground albedo. Finally, Elek and Kmoch (2010) extend Bruneton and Neyret's model to arbitrary atmospheric information. Hosek and Wilkie (2012) created a new model, like Preetham, fitted to modelled data; however, the input data was more accurate (using a physically based atmospheric path tracer rather than previous analytical models) and accounting for the full extraterrestrial solar spectrum.

Bruneton (2016) summarized the eight models briefly described above in excellent detail and compared them against a physics-based atmospheric solver, libRadtran (Mayer and Kylling 2005), and measured data by Kider et al. (2014). RMSE in $\mathrm{mW} / \mathrm{m}^{2}-$ sr-nm was calculated for each of the eight analytical models compared to the measured data for three discrete sky conditions. The mean RMSE of Bruneton's (2016) results are presented in Table 4 with an additional row showing the error achieved by using the physics solver libRadtran.

Table 4: Mean RMSE of analytical sky models tested by Bruneton (2016)

\begin{tabular}{|c|c|}
\hline Model & Mean RMSE (mW/m²-sr-nm) \\
\hline Nishita et al. (1993) & 26.6 \\
\hline Nishita et al. (1996) & 18.3 \\
\hline Preetham et al. (1999) & 88.1 \\
\hline O'Neil (2005) & 49.5 \\
\hline Haber et al. (2005) & 14.7 \\
\hline Bruneton and Neyret (2008) & 11.3 \\
\hline Elek and Kmoch (2010) & 11.3 \\
\hline Hosek and Wilkie (2012) & 41.5 \\
\hline libRadtran (Mayer and Kylling 2005) & 10.4 \\
\hline
\end{tabular}

The ALFA software (Solemma 2017) implements its own analytical sky model by precomputing spectral sky radiance distributions using libRadtran montecarlo with 50 plane parallel layers (Mayer and Kylling 2005). A standard summer midlatitude atmospheric molecular profile is used within the software as defined by the U.S. Air Force Geophysics Laboratory (Anderson et al., 1986). In addition, Shettle's (1989) aerosol profiles are included to consider various weather conditions: clear and hazy. 
Overcast and heavy rain cloud conditions are modelled by adjusting the optical depths at a height of 2-5 km. Ground albedo is included as an additional input parameter (Feister and Grewe 1995) as in the Bruneton and Neyret (2008) model. When a sky model is needed for a calculation, values are simply looked up from precomputed values for 91 solar zenith angles calculated at a single point 10 meters above the surface of the Earth. Comparing the lookup method to full libRadtran calculations, an RMSE of 5.3-5.6 mW/m²-sr-nm was found, but the ALFA sky models have not been validated against measured data.

\subsection{Practical model for spectral sky models}

by Dr. Stanislav Darula, Slovak Academy of Sciences, Slovakia / Dr. Tao Luo, China Academy of Building Research, Beijing, China

For practical use, the division of hemisphere in point of view of application of sky spectral characteristics should respect effectiveness of illumination by natural light in side-lit and top-lit interiors. In Figure 9 is proposed division of hemisphere to two layers in the section. First layer is situated close the horizon with height $47^{\circ}$ and it is significant for illumination of side lit interiors. The second zenith layer can deliver daylight into top lit interiors. To simplify evaluation of measured sky spectral data, first horizontal layer can be divided into sectors respecting sun meridian symmetry of sky luminance pattern, direction to sun, perpendicular direction to the sun meridian and intermediate directions, i.e. summary 8 sectors, Figure 10.

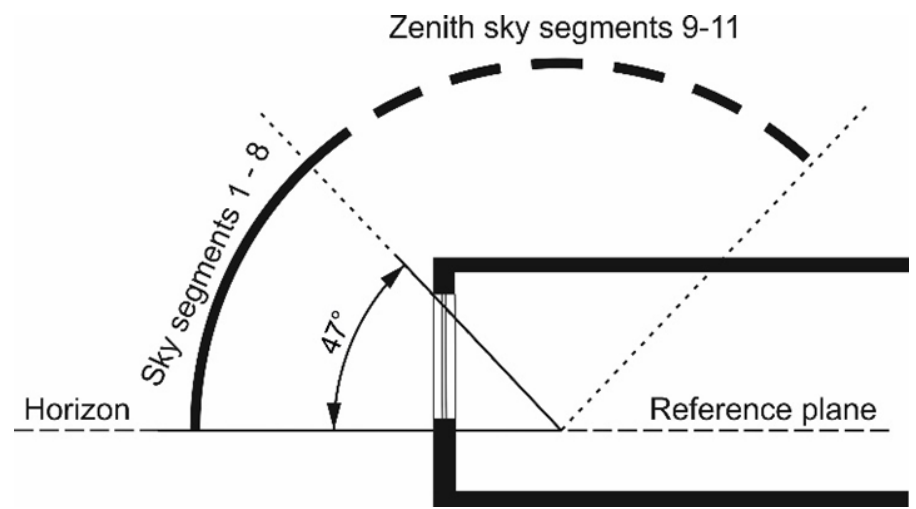

Figure 9: Horizontal and zenith layers of the hemisphere subdivision (cross section)
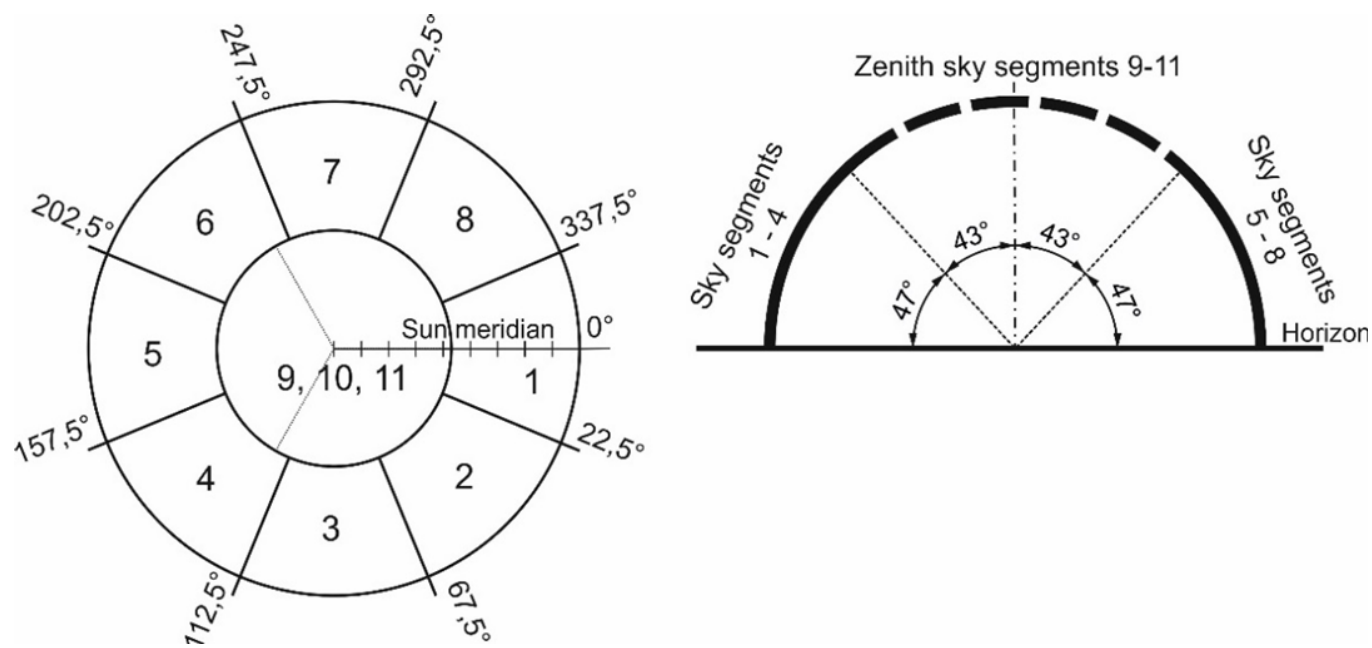

Figure 10: Scheme of proposed hemispherical sectors (plan view) 
Concept of the subdivision of the hemisphere consists of sectors each of which creates almost the same solid angle, Table 5 . Solid angle of the particular horizontal sector is $4.59523 / 8=0.5744 \mathrm{sr}$ while value of the zenith sector is $1.68795 / 3=0.56265 \mathrm{sr}$. Difference is caused by rounding values of horizontal layer to number $47^{\circ}$. Application only one sector in the zenith does not sufficiently respect area of hemisphere from which skylight can be effective illuminated. Therefore, the zenith area is composed as sum of three sectors 9, 10 and 11. In Table 6 are documented values of elevation and azimuthal angles for sector centers measured clockwise from the solar meridian.

Table 5: Solid angles and numbers of sectors in hemispherical layers

\begin{tabular}{|c|c|c|c|c|c|}
\hline \multirow[t]{2}{*}{ Layer } & \multicolumn{2}{|c|}{$\begin{array}{l}\text { Border of the } \\
\text { strip elevation }\end{array}$} & \multirow{2}{*}{$\begin{array}{c}\text { Solid angle } \\
\text { sr }\end{array}$} & \multirow{2}{*}{$\begin{array}{l}\text { Checking of the } \\
\text { sector number }\end{array}$} & \multirow{2}{*}{$\begin{array}{l}\text { Proposed number } \\
\text { of sectors }\end{array}$} \\
\hline & deg & rad & & & \\
\hline \multirow{2}{*}{ Horizontal layer } & 0 & 0.00 & 4.595 & 8.045 & 8 \\
\hline & 47 & 0.82 & 1.688 & 2.955 & 3 \\
\hline Zenith layer & 90 & 1.57 & 1 & \\
\hline Sum & & & 6.283 & & \\
\hline
\end{tabular}

Table 6: Elevation and azimuthal coordinates of sector centres

\begin{tabular}{|l|c|c|c|c|c|c|c|c|c|}
\hline \multirow{2}{*}{ Elevation } & \multicolumn{7}{|c|}{$\begin{array}{c}\text { Azimuth of sector centres, } \\
\text { clockwise from the solar meridian }\end{array}$} \\
\hline Layer & $\begin{array}{c}\text { Centre of } \\
\text { the sector }\end{array}$ & $\mathbf{1}$ & $\mathbf{2}$ & $\mathbf{3}$ & $\mathbf{4}$ & $\mathbf{5}$ & $\mathbf{6}$ & $\mathbf{7}$ & $\mathbf{8}$ \\
\hline Horizontal layer & 23.5 & 0.0 & 45.0 & 90.0 & 135.0 & 180.0 & 225.0 & 270.0 & 315.0 \\
\hline Zenith layer & 90.0 & \multicolumn{7}{|c|}{$/$} & \multicolumn{7}{|c|}{$/$} \\
\hline
\end{tabular}

It is assumed that CCT values of sky elements in a sector without direct sunlight will be without high differences as is presented in Figure 19.

To simulate spectral skylight for daylight utilization in buildings the representative spectral distribution curve of daylight particular sector can be determined as an average value. Azimuths and elevations of the hemispherical area/sector centers should correspond to most important directions: - on the sun azimuth and - on the azimuth with perpendicular direction to the sun meridian.

Scan measuring point are oriented to the North. The sun position is changing during a day therefore the solar meridian of the sector mask should be rotated to be in coincidence with the solar azimuth, as is shown in Figure 11 and Figure 12. Number of measured points in the sectors can differ in dependence on the Sun positions/solar azimuths. In Tab. 3 are presented numbers of measuring points in all sectors used in example in Figure 12. This approach is applied in the evaluation of sky luminance distribution from scan data and can be applied also in study of the measured scan skylight spectral characteristics.

Mentioned solution requires consideration of relevant measuring points in the sector for evaluation of spectral distribution curves and determination representative average curve. Then proposed spectral skylight model can be applied also in evaluation of daylight in rooms with common window orientation as well as in top lit spaces. 


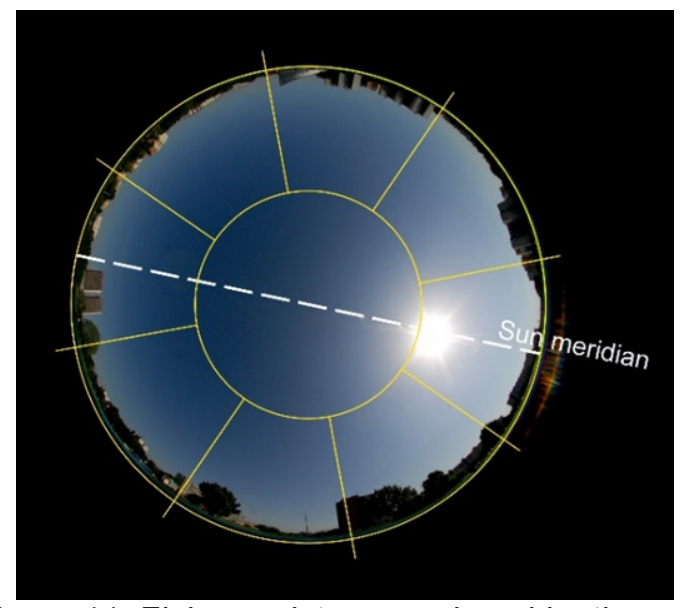

Figure 11: Fisheye picture overlayed by the sector mask

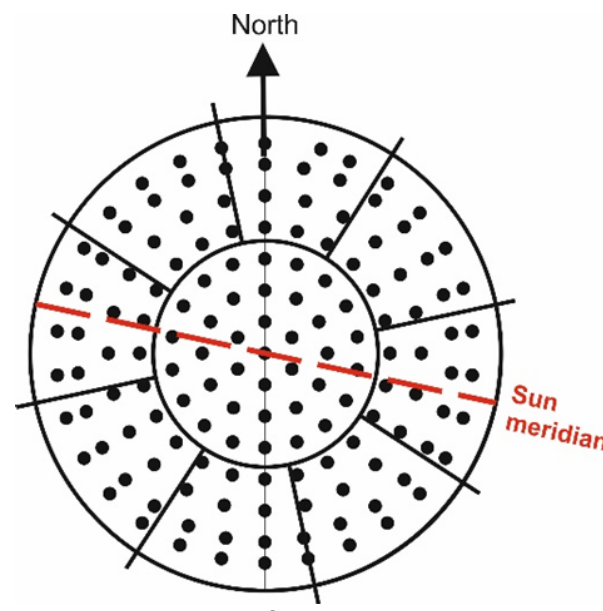

Figure 12: Location of 145 Tregenza point grid (dots) in proposed segments

Table 7: Number of measuring points in sectors used in example in Figure 12

\begin{tabular}{|l||c|c|c|c|c|c|c|c|c|c|}
\hline Sector & $\mathbf{1}$ & $\mathbf{2}$ & $\mathbf{3}$ & $\mathbf{4}$ & $\mathbf{5}$ & $\mathbf{6}$ & $\mathbf{7}$ & $\mathbf{8}$ & Zenith & Sum \\
\hline Number of measuring points & 14 & 12 & 14 & 14 & 14 & 14 & 12 & 14 & 37 & 145 \\
\hline
\end{tabular}

There are three significant colour changes of atmosphere during a day, i.e. - during and after sunrise in the early morning, - during a day and - in the late afternoon before and during sunset. It can assume, that characteristic sky CCT occurs:

- in the early morning when $\gamma_{s}<15^{\circ}$,

- during a day for situations with solar altitude $\gamma_{s}>15^{\circ}$

- in the late evening when $\gamma_{s}<15^{\circ}$.

The clear sky conditions offer study of azimuthal and elevation influences on the spectral light distribution on the hemisphere. The ISO 15469:2004(E)/CIE S 011/E:2003 (CIE 2003) with its parameterization offers method for classification of the sky luminance distribution. 


\section{Material properties}

by Dr. J. Alstan Jakubiec, University of Toronto, Canada

\subsection{Glazing materials}

Lawrence Berkeley National Laboratory's (LBNL) International Glazing Database (IGDB) contains spectrally resolved transmission, front reflectance, and back reflectance measurements of 1000s of commercially available film, coated, laminate and monolithic glazing products. The Optics tool (https://windows.lbl.gov/software/optics) allows users to combine multiple glazing layers, films, and laminates to obtain a complete spectral transmission and reflection profile of a glazing assembly. Associated measures such as $T_{v i s}, T_{\text {sol }}, T_{u v}$, and tristimulus colour values are also calculated. Figure 13 illustrates a double pane glazing assembly constructed in Optics from IGDB data.

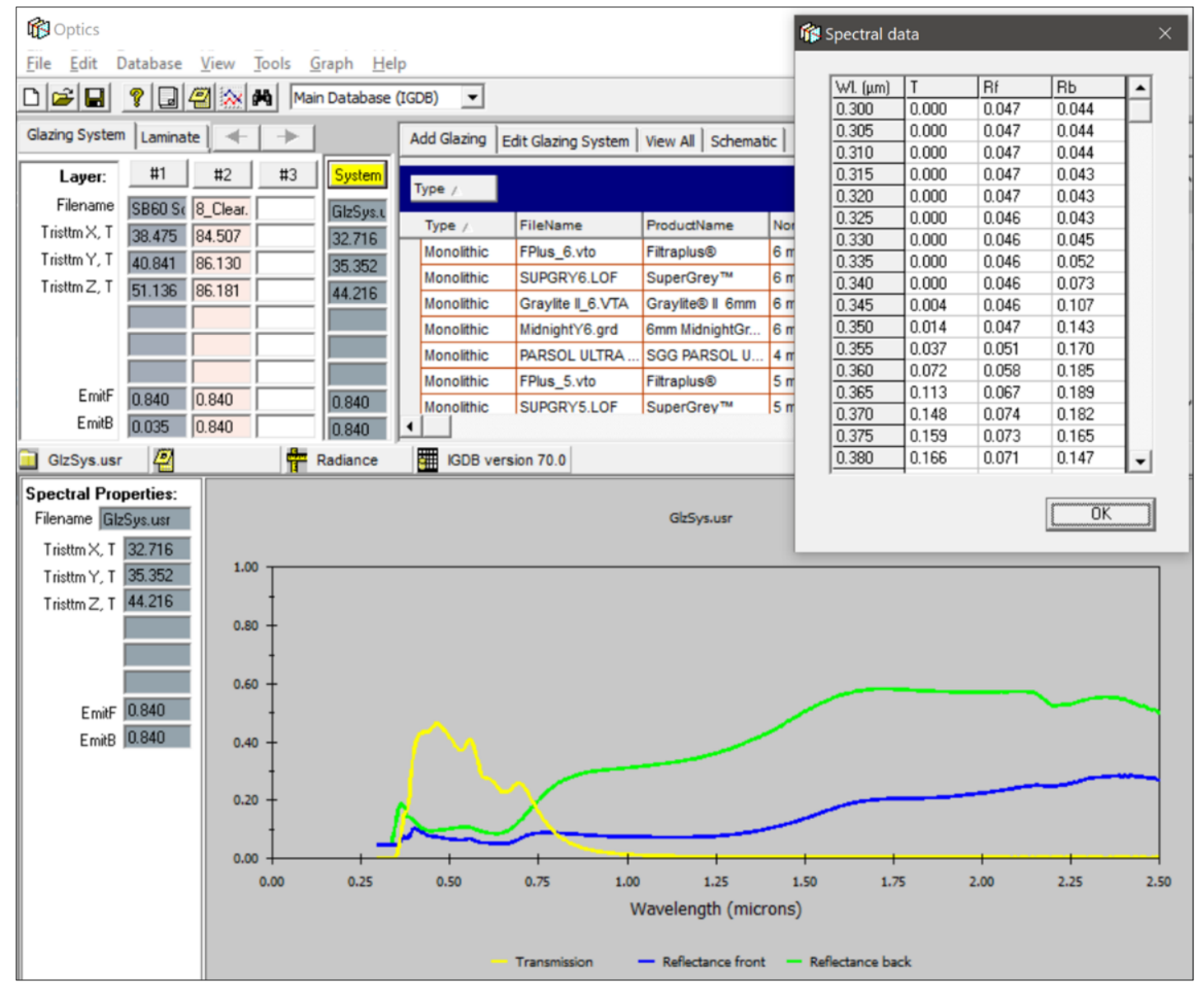

Figure 13: View of a double-glazing assembly's spectral properties in Optics

\subsection{Opaque materials}

Opaque reflectance properties can be quantified spectrally per-wavelength using a reflectance spectrophotometer or spectroradiometer. Jakubiec has compiled a database of 1204 full-spectrum measurements primarily collected during the 11 studies shown in Table 8. Figure 14 illustrates the colorimetric distribution of these measurements in the CIE $L^{*} a^{*} b^{*}$ colour space. CIE $L^{*} a^{*} b^{*}$ is a perceptually uniform, 
three-dimensional colour space where the $L^{*}$ parameter indicates lightness, $a^{*}$ describes a colour component from green to red and $b^{*}$ describes a colour component from blue to yellow. Because of CIE L*a*b*'s perceptual uniformity, colour similarity can be computed simply by the distance from any point $\left(a^{*}, b^{*}\right)$. Circles are drawn on top of Figure 14 identifies colour values nearby colour points ranging from neutral $(0$, $0)$ to red $(52,36)$ to purple $(22,-16)$. Figure 15 plots the distribution of spectral reflectance measures for four of these regions.

Table 8: Spectral reflectance data sources

\begin{tabular}{|l|l|c|c|}
\hline & Authors & Date & $\begin{array}{c}\text { Number of } \\
\text { Measures }\end{array}$ \\
\hline 1 & Vrhel et al. & 1994 & 354 \\
\hline 2 & Ward & 1995 & 17 \\
\hline 3 & Jakubiec and Reinhart & 2014 & 7 \\
\hline 4 & Glassner & 2014 & 21 \\
\hline 5 & Jakubiec & 2016 & 106 \\
\hline 6 & Balakrishnan and Jakubiec & 2016 & 11 \\
\hline 7 & Jones and Reinhart & 2017 & 76 \\
\hline 8 & Quek and Jakubiec & $2018-19$ & 161 \\
\hline 9 & Kong and Jakubiec & 2019 & 180 \\
\hline 10 & Balakrishnan and Jakubiec & 2019 & 44 \\
\hline 11 & Jakubiec et al. & 2019 & 303 \\
\hline
\end{tabular}

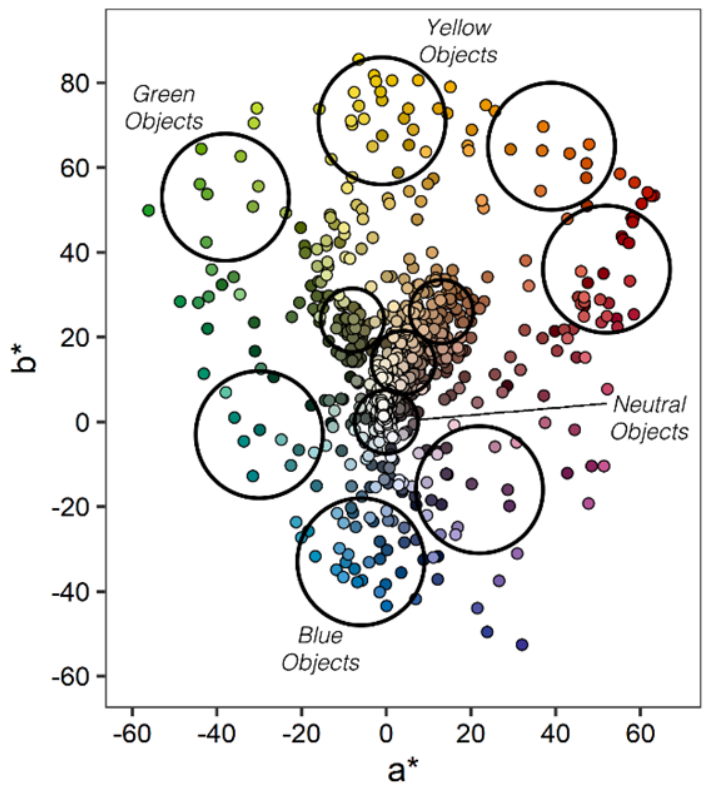

Figure 14: Colour ranges indicated by black circles displayed in the CIE $L^{*} a^{*} b^{*}$ colour space 


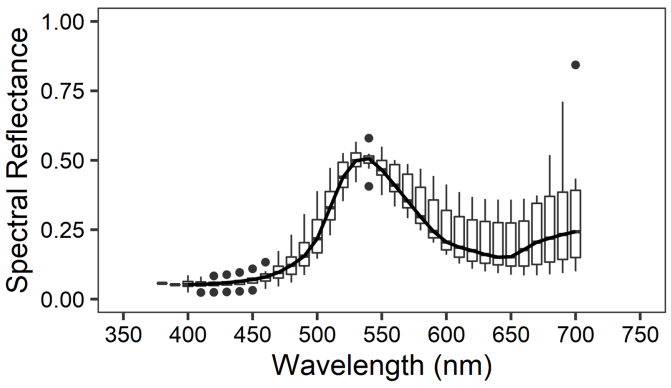

(a) Green Objects

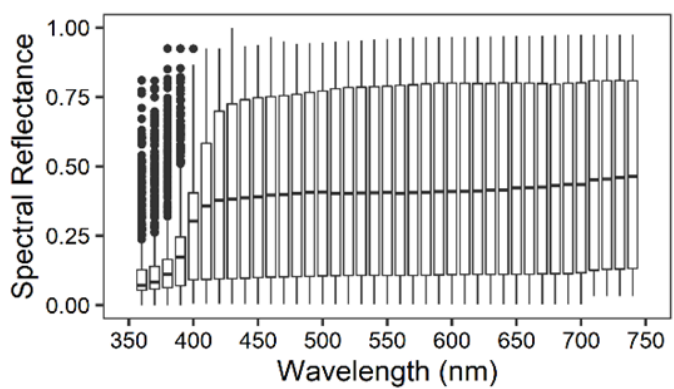

(c) Neutral Objects

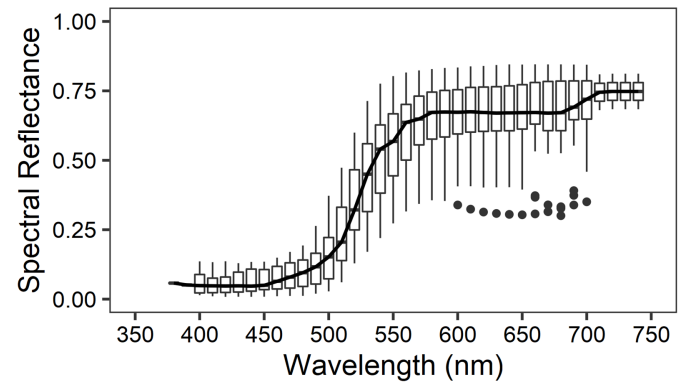

(b) Yellow Objects

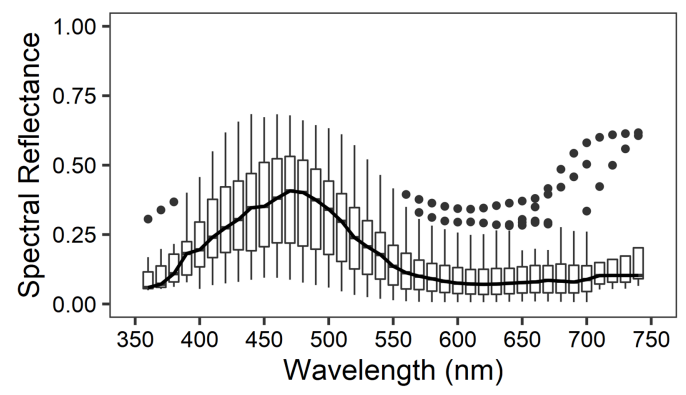

(d) Blue Objects

Figure 15: Selected spectral reflectance distributions of similar colors identified in Figure 14

The database of reflective measurements is available publicly from http://www.spectraldb.com/, and all data can be downloaded in raw comma separated value format from GitHub: https://github.com/C38C/SpectralDB. 


\section{Simulation software supporting spectral calculations}

\subsection{Introduction}

\section{by Dr. Priji Balakrishnan}

Current daylight simulation platforms are based on three-dimensional colour spaces, such as RGB (Red, Green, Blue), for predictive renderings. Computations in RGB colour space does not suffice the needs of designers when they have to predict colour shifts, colour-dependent lighting metrics (like circadian light), and changing visual perceptions occurring under different sky conditions.

Spectral simulations or spectral rendering platforms are based on simulating the visible spectral information of light. Their use is evident in the field of psychophysical analysis, where visual psychophysicists need to produce complex simulated stimuli for their experiments. However, these experiments use simulated scenes created using objects and mostly illuminated by artificial sources of light.

Spectral lighting simulation that can achieve the physical accuracy of light is currently based on the Radiance lighting and visualization platform (Ward, 1994). Ruppertsberg and Bloj (2006) validated Radiance for colour and luminance accuracy using an N-step method to perform multi-spectral simulations. The $\mathrm{N}$-step algorithm divides the spectrum into $\mathrm{N}$ consecutive wavebands, and a simulation is performed in each of these $\mathrm{N}$ channels rather than the standard single RGB simulation. Ruppertsberg and Bloj also concluded that for spectral renderings using $N=3, N=9$, and $N=81$ steps, the 9-channel simulation achieved higher accuracy than the 3-channel but increasing it to 81 channels did not improve the results.

In the field of architecture and daylighting, Inanici, Brennan, and Clark (2015) used Ruppertsberg and Bloj's N-step method for spectral simulations, to determine circadian lighting. They analyzed interior scenes for circadian and photopic lux using spectral skies from measured CCT values. For ease of use of the N-step method by architects and lighting designers, Inanici, Brennan, and Clark also released LARK - an opensource plugin for the software Rhinoceros 3D. LARK can be used for spectral simulations to evaluate circadian lighting (Inanici and ZGF Architects, 2015). ALFA (Adaptive Lighting for Alertness) is also a Radiance based spectral simulation platform to compute circadian lighting. ALFA performs simulation on 81-colour channels, unlike LARK which is set up to run a maximum of 9-channel simulations (Solemma, 2017).

LARK and ALFA are the two currently user-friendly programs to perform spectral, physically accurate daylight simulations. They are both based on Radiance and is operated through the popular 3D modelling program for architects - Rhinoceros 3D

\subsection{Simplification of spectral sky models - spectral prefiltering}

\section{by Dr. David Geisler-Moroder, Greg Ward, Taoning Wang}

In 2002, Ward and Eydelberg-Vileshin (2002) developed an improvement to RGB rendering by using an algorithm called "spectral prefiltering". In this method, the RGB values of the surface reflectances are calculated from their spectral representations 
such that the direct-diffuse component is exact when illuminated by the respective light source. Compared to full-spectral rendering, the main drawback of this method is that scenes lit by more than a single light source or with specular and/or multiple reflections are not rendered accurately. However, they show that spectral prefiltering minimizes colour errors in scenes with a single dominant illuminating spectrum. Also, for scenes with various illuminating spectra, the prefiltering approach is no worse than the naïve RGB rendering approach. In the same paper (Ward and Eydelberg-Vileshin, 2002), they also show that a good selection of the used colour space can improve the rendering accuracy. Comparing the CIE XYZ, sRGB and Sharp RGB colour spaces, they show that the last performs best. Combining both, the spectral prefiltering algorithm and the Sharp RGB colour space delivers the best results with the least deviation from the full spectral ground truth rendering.

We assume that applying the spectral prefiltering method to daylight simulations can also improve the accuracy of colour evaluations as well as calculations based on various spectral weighting functions (e.g., melanopic action spectrum (CIE 2018)). However, there are still some open questions how the method can be best implemented.

Starting from a full spectral sky definition, the first question is how to define the dominant illuminating spectrum. A possible approach would be to evaluate the spectral illuminance at the window, which would however be different for every window orientation in the building. Another option could be to use the spectral illuminance at an unobstructed horizontal plane. Both approaches require a pre-calculation to determine the respective spectral illuminance. To avoid any pre-calculation, another approach could be to use the spectral distribution of the sun - if available - or of the brightest sky area.

For prefiltering the RGB values of materials in the scene the first proposal would be to only prefilter the RGB values of the windows in the scene. This means that the light entering the room is rendered accurately and with that also the light directly incident at an observer's eye in this room. Behind this is the assumption that the vertical illuminance at eye level is also mainly influenced by the direct contribution from the window.

In a next step the assumptions and proposed approaches should be validated with renderings based on spectral skies and spectral transmission properties of windows against full spectral renderings. The impact on colour accuracy and evaluations such as non-image-forming effects (e.g., equivalent daylight illuminance describing melanopic effects) need to be analyzed.

\subsection{Colour modified Perez sky}

by Dr. Jan Wienold, Ecole Polytechnique Fédérale de Lausanne, Switzerland, Aicha Diakite-Kortlever, Technische Universität Berlin, Germany

In recent years, the evaluation of colorimetric and spectral quantities in daylight simulations became more and more important but lacking a spectral or colour sky model. In daylight simulations for science and practice the All-Weather Model (Perez et al. 1993) is widely used as sky luminance distribution and is implemented in the RADIANCE software package ("gendaylit”). 
To fill the gap of missing spectral information of a simulated sky, gendaylit was modified to create a colour output but keeping the luminance information according to the AllWeather Model (Perez et al. 1993).

This implementation follows an approach using data-driven luminance-related spectral sky models as presented in Section 3.1. As a first step the colour information, represented by the CCT, is calculated for each ray hitting the sky from the corresponding luminance using one of the spectral sky models, as enlisted in Table 3. The daylight chromaticity $X_{D}$ within the range of 0.250 to 0.380 can then be calculated from the CCT according to CIE (2018b), with a distinction in calculation for two CCT regions: $4000 \mathrm{~K}<\mathrm{CCT} \leq 7000 \mathrm{~K}$ and $7000 \mathrm{~K}<\mathrm{CCT}<25,000 \mathrm{~K}$. Subsequently, the daylight chromaticity $\mathrm{Y}_{\mathrm{D}}$, also known as the CIE daylight locus, can be calculated from $\mathrm{X}_{\mathrm{D}}$. Finally, the colour properties are transformed to the RADIANCE RGB colour space. Moreover, the daylight chromaticities can also be used to reconstruct the spectral power distribution SPD for each patch using the CIE daylight illuminants defined in CIE (2018b). The computed SPD can be then weighted with any given action function. For example, the $\alpha$-optic quantities can be determined according to CIE (2018). A preliminary implementation was limited to two spectral sky models based on the measurements conducted in Berlin and defined for the CIE sky types CIE 3 and CIE 12. One significant limitation of the study was the matching of the Perez luminance sky models with spectral sky models related to the CIE skies. The sky clearness $\varepsilon$ is used to separate between the sky types (for CIE 3: $\varepsilon<1.065$; for CIE $12 \varepsilon \geq 4.5$ ).

\subsection{Lark}

by Dr. J. Alstan Jakubiec, University of Toronto, Canada

Lark (Inanici et al. 2015) utilizes Radiance to perform brute force nine-channel spectral lighting calculations. The nine visible wavelength channels used by Lark are derived from spectral ranges for the red $(R)$, green $(G)$, and blue $(B)$ channels in native Radiance. The resulting spectral range of each simulation channel in Lark is as follows: B: $380-422$ nm, $422-460 \mathrm{~nm}, 460-498 \mathrm{~nm}$; G: $498-524 \mathrm{~nm}, 524-550 \mathrm{~nm}, 550-586 \mathrm{~nm}$; R: $586-650 \mathrm{~nm}, 650-714 \mathrm{~nm}, 714-780 \mathrm{~nm}$. Lark takes user input spectral source data at any evenly spaced wavelength and converts it to the nine spectral bins for simulation. This is also true for skylight spectra, which means that the spectral power distribution must be defined by the user, for example using the Daylight Series Calculator (Color Science Laboratory 2002) that the authors of Lark recommend. In this case, the spectral power distribution is uniform across the sky, not varying with location in the sky dome. Sky luminance is derived using standard Radiance tools such as gensky or gendaylit. The solar disk in Lark is modelled as equal energy. Figure 16 illustrates the GUI of Lark for running a nine-channel simulation. 


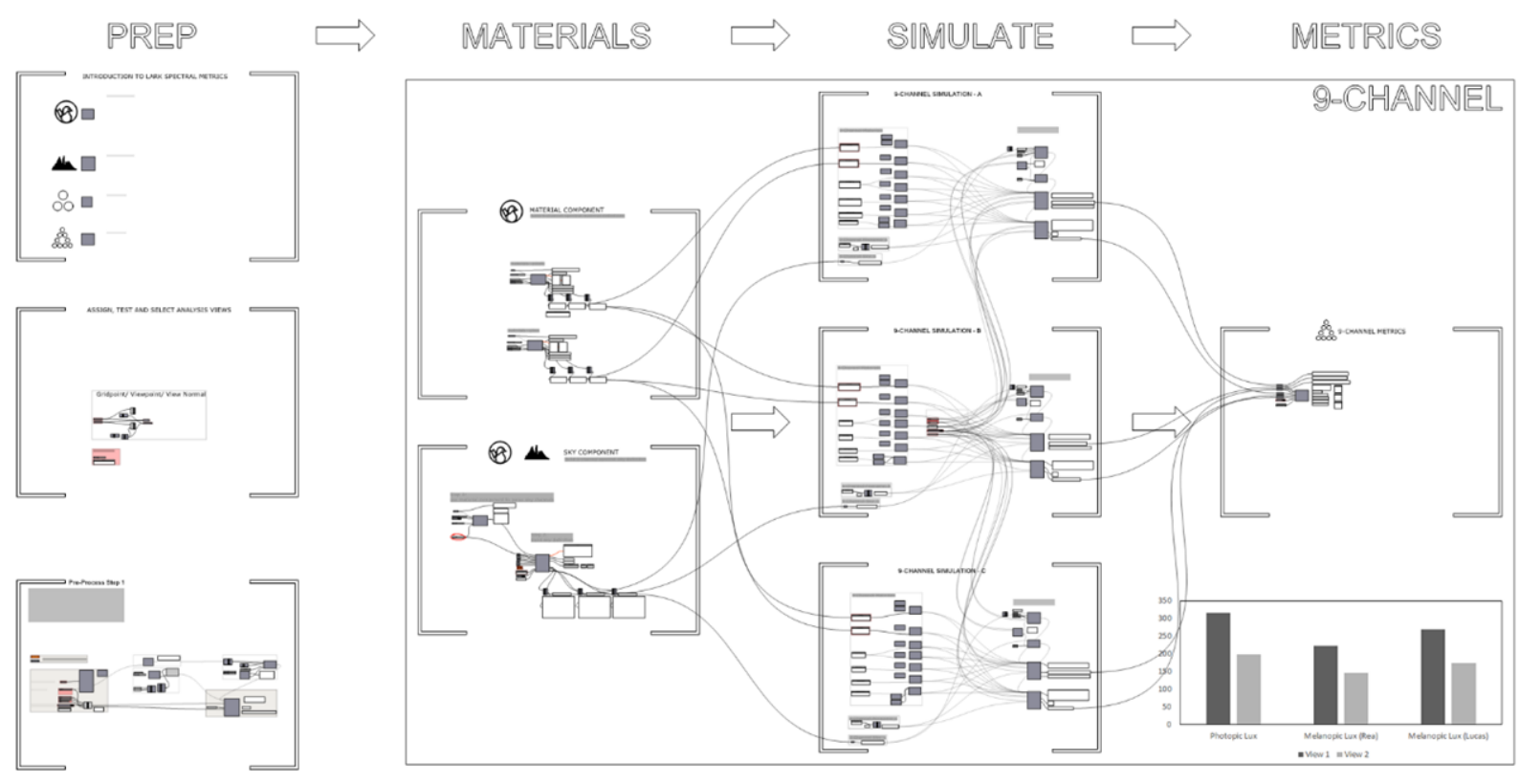

Figure 16: Lark interface displaying step-by-step process of the nine-channel calculation in three steps

Lark produces melanopic spectral response curve-weighted luminance renderings and illuminance values (melanopic lux) using the Rea (2015) and Lucas (Lucas et al. 2014) curves. Because of its brute force nature, a simulation in Lark will take approximately 3-times longer than a standard Radiance rendering for the same parameters. Lark is distributed as a free and open-source plugin for Rhinoceros 3D and Grasshopper.

\subsection{ALFA}

by Dr. J. Alstan Jakubiec, University of Toronto, Canada

ALFA-Adaptive Lighting for Alertness-extends the Radiance lighting engine to conduct simulations in 81 colour channels. ALFA accurately accounts for the action of each of the five photoreceptors in the human eye - including the melanopsincontaining cells that help regulate alertness and sleep. To carry out 81-channel renderings and illuminance calculations, ray trees produced by Radiance are parsed by a program called spectree. Spectree inserts a source spectrum at the terminus of each ray path (e.g. at a luminaire or the sky), and then moves backward toward the ray origin, accounting for spectral reflectances and/or transmittances at each material interaction. The resulting radiance spectra are nearly identical to those produced by a brute force approach (which involves repeating a 3-channel Radiance simulation run 27 times to cover the 81 spectral channels), but the spectree approach is $10-15$ times more CPU efficient. Renderings and sensor-grid simulations in ALFA are carried out progressively, meaning noisy results are delivered quickly and then smoothed out over time. For most lighting scenes, accurate values are achieved after merely a few passes, often in a matter of seconds. Figure 17 shows a diagram of a ray path with 3bounces and how the spectrum is modified between the source and the sender. 


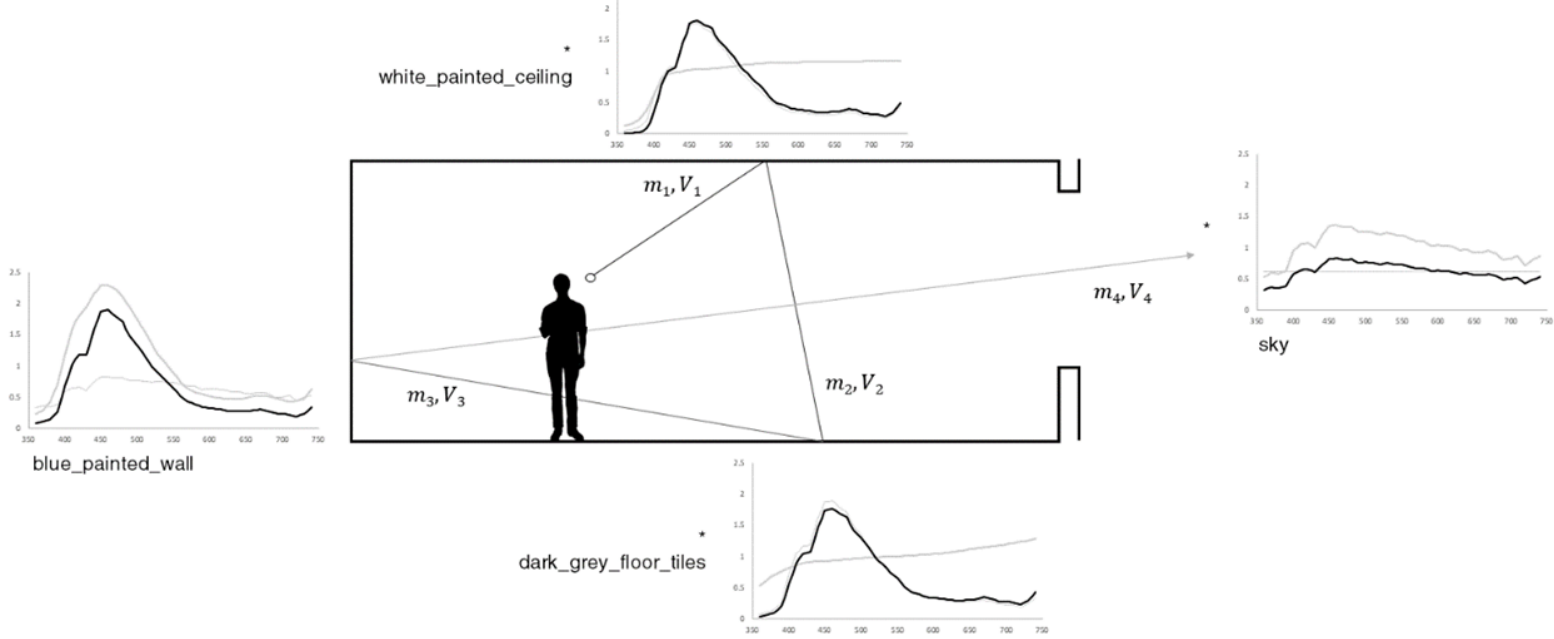

Figure 17: Spectree process of modifying sky irradiance contribution as a function of ray-surface reflections and material properties

ALFA is distributed as a plugin for Rhinoceros 3D. The spectree engine is tied to the plugin, meaning that simulations cannot be run independently from the user interface. The colored sky model used by ALFA is described in Section 3.2, analytical spectral sky models. Electric light sources are included in ALFA through import of IES files, an industry standard format for representing measured luminous intensity information in three-dimensions; however, IES files do not include spectral information. ALFA applies a user-settable spectral power distribution (SPD) on top of the IES luminous intensity data, and the result is a spectral intensity adjusted to maintain the same luminous flux as the original IES data.

ALFA calculates melanopic illuminance (Lucas et al. 2014), photopic illuminance, and $\mathrm{M} / \mathrm{P}$ ratios based on its spectral calculations and can illustrate those across a work plane sensor grid or a vertical sensor grid. Work plane and vertical sensor results can be exported as a comma separated value (CSV) file with the full spectral irradiance. ALFA can also calculate hyperspectral 81-channel HDR images and display photopic and melanopic luminance; however, their analysis is only possible within the software. Figure 18 depicts the ALFA interface.

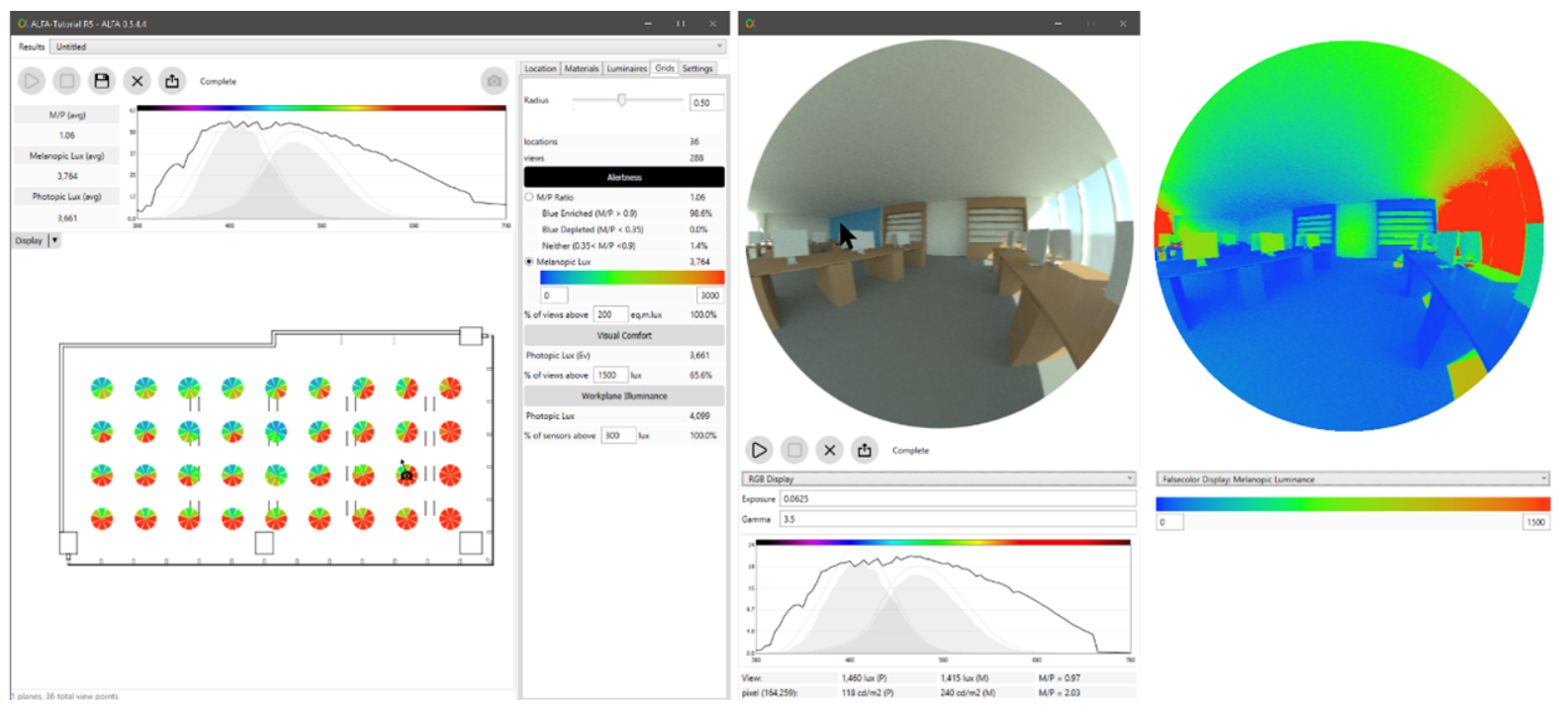

Figure 18: ALFA interface for displaying melanopic vertical illuminance and hyperspectral renderings 


\subsection{LARK and ALFA comparison}

\section{by Dr. Priji Balakrishnan}

LARK and ALFA are the two most accessible and easy to use interfaces for the daylight community to perform spectral daylight simulations. Both platforms were created to compute circadian lighting metrics, however both the platforms can produce visual spectral renders of the scenes simulated. The visual renders have richer colour information and represent physically accurate colour perceptions when compared to non-spectral standard RGB (Red, Green, Blue) daylight simulations.

A summary of the different parameters used in ALFA and LARK, along with parameters needed for a non-spectral simulation using a monochromatic luminance-based PEREZ sky, is listed in Table 4, and adopted from the paper Balakrishnan and Jakubiec (2019).

LARK and ALFA mainly differ in the way the sun and sky are represented. While LARK takes measured global spectral sky irradiance as an input, it lacks an atmospheric profile found in ALFA. Without an atmospheric profile, colour renditions of the lowangle sun in the sky cannot be depicted. ALFA's atmospheric profile is currently based on a standard summer midlatitude atmospheric molecular profile elaborated in Section 3.2 (Analytical spectral sky models). ALFA has the potential to improve the accuracy of colour renditions and spectral outputs by including location-specific atmospheric profiles.

LARK can additionally take Correlated Colour Temperature (CCT) of the sky as an input. If CCT is used, it has to be converted to spectral irradiance data based on the definitions of CIE standard illuminants (Wyszecki and Stiles, 1982; Inanici et al., 2015). Using measured spectral irradiance data gives more accuracy than the standard sky conditions represented by the CIE illuminants. A comparison of visual, spectral, and colour difference comparisons between LARK and ALFA for different urban environments can be found in the paper by Balakrishnan and Jakubiec (2019). 
Table 9: Comparison of simulation parameters of LARK, ALFA, and non-spectral simulation platform

\begin{tabular}{|c|c|c|c|}
\hline Parameters & LARK & ALFA & $\begin{array}{l}\text { Non-spectral } \\
\text { simulation using } \\
\text { PEREZ sky }\end{array}$ \\
\hline Sky input & $\begin{array}{l}\text { Measured spectral } \\
\text { irradiance, global solar } \\
\text { irradiation, location, } \\
\text { time }\end{array}$ & $\begin{array}{l}\text { Pre-computed spectral } \\
\text { sky irradiance in } \\
\text { libRadtran, location, } \\
\text { time }\end{array}$ & $\begin{array}{l}\text { Non-spectral and } \\
\text { luminance-based sky, } \\
\text { global solar irradiation, } \\
\text { location, time }\end{array}$ \\
\hline Sun & $\begin{array}{l}\text { Represented as a non- } \\
\text { spectral equal energy } \\
\text { white source }\end{array}$ & $\begin{array}{l}\text { Represented as a sun } \\
\text { with spectral } \\
\text { information, lending it } \\
\text { colour. }\end{array}$ & $\begin{array}{l}\text { Represented as a non- } \\
\text { spectral equal energy } \\
\text { white source }\end{array}$ \\
\hline Atmosphere & $\mathrm{n} / \mathrm{a}$ & $\begin{array}{l}\text { Sky spectra is } \\
\text { computed using a } \\
\text { standard mid-summer } \\
\text { latitude atmospheric } \\
\text { profile. }\end{array}$ & $\mathrm{n} / \mathrm{a}$ \\
\hline $\begin{array}{l}\text { Sky } \\
\text { condition }\end{array}$ & $\begin{array}{l}\text { Determined by the } \\
\text { global irradiance input } \\
\text { to gendaylit program. }\end{array}$ & $\begin{array}{l}\text { Users can choose from } \\
\text { overcast, hazy, heavy } \\
\text { rain clouds }\end{array}$ & $\mathrm{n} / \mathrm{a}$ \\
\hline $\begin{array}{l}\text { Simulation } \\
\text { format }\end{array}$ & 9-channel & 81-channel & $\begin{array}{l}\text { Standard 3-channel } \\
\text { RGB format }\end{array}$ \\
\hline $\begin{array}{l}\text { Material } \\
\text { input }\end{array}$ & $\begin{array}{l}\text { Spectral material } \\
\text { reflectance }\end{array}$ & $\begin{array}{l}\text { Spectral material } \\
\text { reflectance }\end{array}$ & $\begin{array}{l}\text { RGB material } \\
\text { reflectance }\end{array}$ \\
\hline
\end{tabular}


If spectral characteristics of daylight on the façade are relevant, spectral sky models based on patch measurements or integral measurements on titled planes are preferred, as the spectral power distribution of specific regions of the sky can vary largely (Nayatani and Wyszecki 1963, Diakite and Knoop 2019b). Horizontally positioned integral measurements, which cover a smaller CCT bandwidth, will provide information about an average condition for assessments in which the assessment direction is unknown or variable.

\subsection{SDPDs}

by Aicha Diakite-Kortlever and Dr. Martine Knoop, Technische Universität Berlin, Germany

Spectral daylight potential diagrams (SDPD) diagrams display the orientation dependent integral CCT of sky light received at a horizontal plane and vertical planes of any orientation (Figure 19). The SDPDs offer an indication about the deviation from $6500 \mathrm{~K}$, currently taken as the standard CCT of daylight, also in urban settings. These diagrams can represent

1. momentary daylighting conditions (momentary SDPDs)

SDPDs that present the momentary daylight conditions are snapshots of different sky conditions, based on actual, not averaged, daylight measurements.

2. reference conditions (statistical SDPDs)

The statistical SDPDs can be used to show the dynamic bandwidth of CCT on façades throughout the year.

The CCTs of both types of SDPDs can either be used directly by designers or can be included in software to gain insight into the impact of orientation, weather conditions and of obstructions on colorimetric characteristics of daylight in the urban environment.

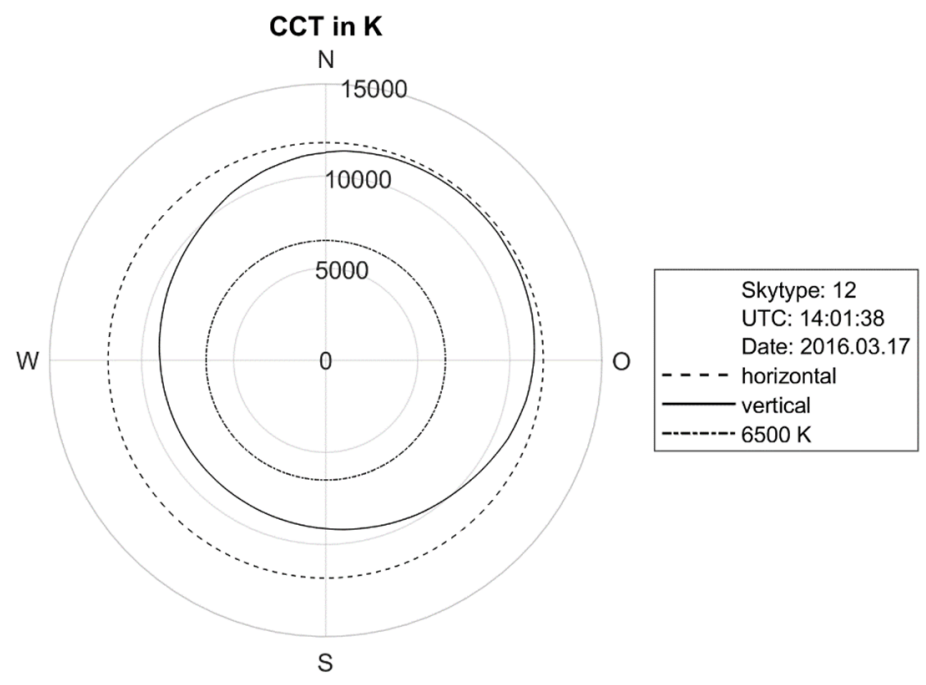

Figure 19: Example of a momentary SDPD, reflecting the momentary CCT on façades of any orientation (vertical) and the horizontal plane, in comparison the D65 standard (6500 K) under clear sky conditions (March 17, 2016) 
SDPDs are based on sets of spectral sky data generated and processed at the TU Berlin and can be obtained on request (https://www.li.tu-berlin.de/menue/equipment/ dms/indoor daylight/request form/). The underlying sky light measurements were conducted at the daylight measuring site of the TU Berlin, where spectral radiance measurements of sky light without direct sunlight were performed by a custom-made spectral sky scanner (Section 2.1.1).

\subsection{Urban aesthetics}

\section{by Dr. Priji Balakrishnan}

Light distribution and colour are fundamental in determining the character and quality of a space. The spatial distribution of colour and form in the built environment lends, at different scales of city, street or individual building, its identity and visual quality. Concisely it influences urban aesthetics and how people feel about cities. Figure 20 illustrates the changes in the appearance of a residential building in Singapore from morning to evening.

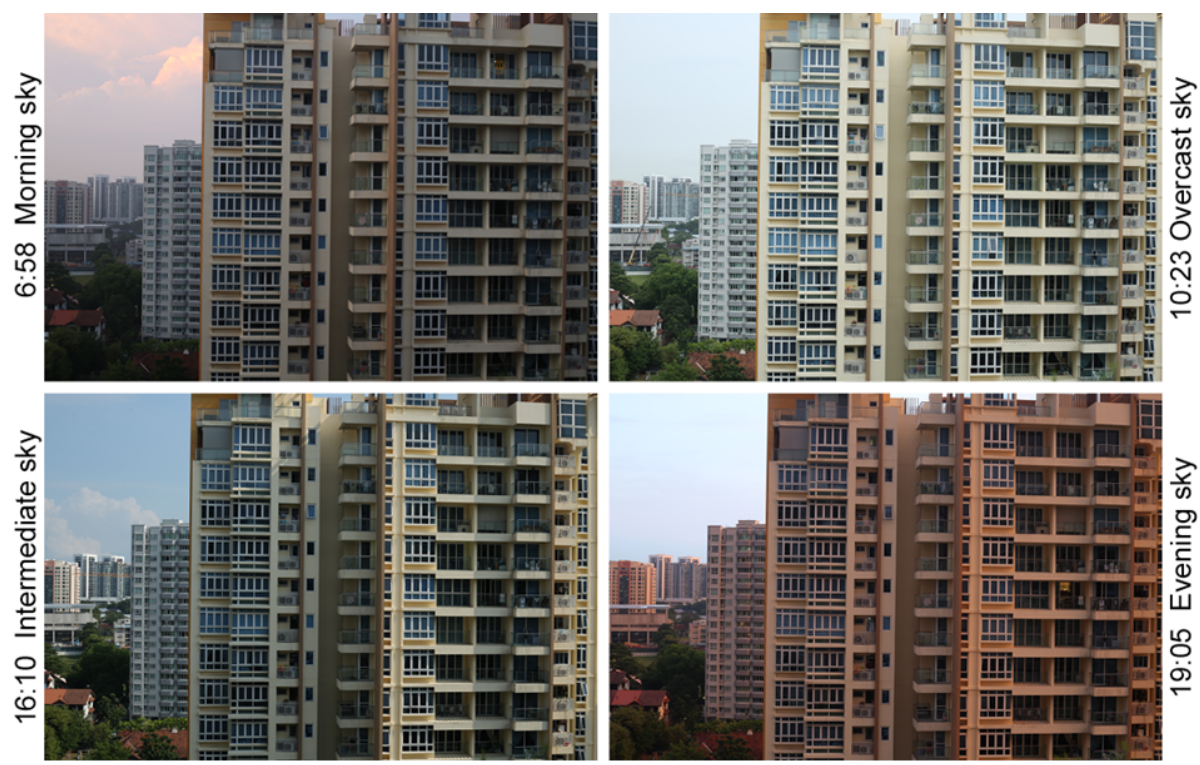

Figure 20: Appearance of a residential building in Singapore under different sky conditions.

The sky is the essential light source when it comes to illuminating the outdoors during the day. Hence, the changing spectral properties of the sky is what influences the way we perceive outdoor environments. For example, our perceptions of time and scale, emotional and cultural responses of visual quality and identity changes from morning to evening or northern to southern latitudes due to difference in the spectral properties of the sky. Therefore, it is essential for a designer to understand the influence of sky colour on these perceptions of urban aesthetics for any modification, continuation or improvement that may be required.

A study by Balakrishnan and Jakubiec (2019) compared the potential of using ALFA and LARK spectral platforms to render the aesthetics of changing sky conditions for urban environments of various materiality. The authors performed visual, spectral and colour difference comparisons of actual measurements with spectral renders and outputs from the simulation. Figure 21 shows the visual comparisons between HDR (High Dynamic Range) photographs, non-spectral simulation renders (using PEREZ sky), and spectral simulation renders (LARK and ALFA) for three urban environments. 
Visual comparison of Figure 21 focuses on the aesthetic qualities of direct light (light from the sun) in urban environments with predominantly plaster, vegetation, and reflective materials.

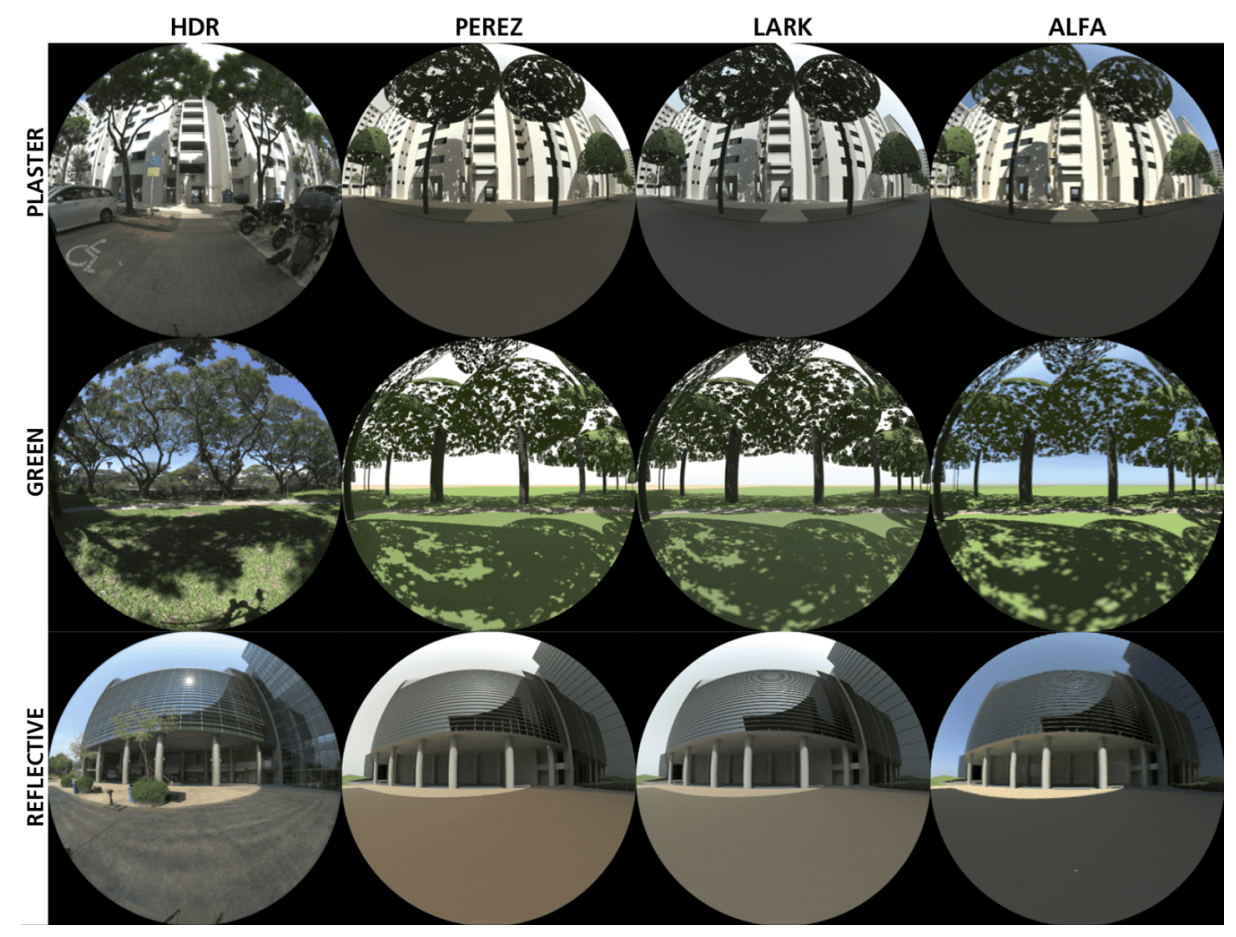

Figure 21: Comparisons of the effects of direct light in HDR photograph, non-spectral PEREZ render, spectral LARK and ALFA renders of different urban environments under clear sky conditions.

The applications of collecting location-specific spectral sky information and testing spectral simulation tools go beyond the non-visual effects of lights. For example, in the doctoral research by Balakrishnan (2019), the author's study concluded that in equatorial climates, like Singapore, plaster facades best represent time varied colour renditions of daylight. Spectral platforms like ALFA and LARK can be used by designers to simulate urban materiality or colors, therefore, helping them create a visual vocabulary of location-specific aesthetics using daylight. In commercial image rendering programs like $\mathrm{V}$-ray and Maxwell colour temperature and atmospheric parameters like turbidity, Ozone levels can be input to describe the characteristic of the sky (light source) for rendering images. 


\section{Outlook}

\subsection{CIE activities}

by Dr. Martine Knoop, Technische Universität Berlin, Germany

In 2020, a CIE Technical Committee was installed to review geographical, seasonal, and time-of-day variations in the spectral power distribution of daylight, when represented by $D$ (daylight) illuminants, and to provide spectral information for CIE standard general sky types (CIE 2003).

The main scientific and technical objectives of this TC are listed below:

- To organize a worldwide spectral daylight data collection campaign, so as to collect spatially resolved spectral measurements as well as global (hemispherical) spectral measurements.

- To review daylight illuminants (CIE 2018b, Section 4.1.1.2 and 4.1.2), addressing seasonal and geographical (CIE 2018b, Section 4.1.2, Note 1), as well as time-of-day variations in the spectral power distribution of daylight, within the range of $380 \mathrm{~nm}$ to $780 \mathrm{~nm}$.

- To make a proposal for updating the CIE reconstitution procedure to calculate daylight illuminants at a nominal correlated colour temperature (CIE 2018b, Equation 4.7 - 4.11), considering seasonal, geographical, and time-of-day variations.

- To provide spectral information for the CIE standard general sky types (CIE 2003)

This information will allow for an appropriate characterization of daylight to unfold the potential of daylight in lighting design and research when considering human responses, such as non-visual responses to light. Designers and scientists can consider and quantify this potential in the development and design of human centered lighting solutions. With an updated reconstruction procedure, spectrally resolved information on daylight can be obtained from correlated colour temperature or chromaticity coordinates. This allows, for example, the use of inexpensive colour sensors to obtain an approximate SPD without having to rely on spectroradiometers. In addition, the daylight's SPD can be reflected in only one value, its correlated colour temperature. This is useful in the presentation of daylight conditions, as for example used in the spectral sky models. 
Amt für Statistik Berlin-Brandenburg. 2018. Statistisches Jahrbuch Berlin 2018

Anderson, G. P., Clough, S. A., Kneizys, F., Chetwynd, J. H., \& Shettle, E. P. (1986). AFGL atmospheric constituent profiles $(0.120 \mathrm{~km})$. Retrieved from

https://apps.dtic.mil/sti/pdfs/ADA175173.pdf

Balakrishnan, P. \& Jakubiec, J.A. (2019). Spectral Rendering with Daylight: A Comparison of Two Spectral Daylight Simulation Platforms. In: Proceedings of the 16th IBPSA International Conference BS2019, Rome, Italy, September 3-4, 2019

Balakrishnan, P. (2019). Measuring and Modelling Equatorial Light. (Doctoral dissertation, Singapore University of Technology and Design)

Bruneton, E. (2016). A qualitative and quantitative evaluation of 8 clear sky models. IEEE Transactions on Visualization and Computer Graphics, 23(12), pp. 2641-2655.

Bruneton, E., \& Neyret, F. (2008). Precomputed atmospheric scattering. Computer Graphics Forum, 27(4), pp. 1079-1086.

Chain, C., Dumortier, D., \& Fontoynont, M. (1999a). A comprehensive model of luminance, correlated colour temperature and spectral distribution of skylight: comparison with experimental data. Solar Energy, 65(5), 285-295.

Chain C., Dumortier, D., \& Fontoynont, M. (1999b) Integration of the spectral and directional component in sky luminance modelling. In: CIE 133:1999 Proceedings of the 24th Session of the CIE, Warsaw, Poland. 24 to 30 June 1999:248-252.

Chain C. (2004) Caractérisation spectrale et directionnelle de la lumière naturelle: Application à I Éclairage des Bâtiments.: PhD Dissertation. ENTPE, Laboratoire des Sciences de l'Habitat, Département Génie Civil et Bâtiment, Vaulx-en-Velin, France.

CIE (1994). CIE 108:1994 Guide to recommended practice of daylight measurement. Vienna, Austria: International Commission on Illumination (CIE).

CIE (2003). CIE S 011/E:2003/ISO 15469:2004: Spatial Distribution of Daylight - CIE Standard General Sky. Vienna, Austria: International Commission on Illumination (CIE).

CIE (2018) CIE S 026/E:2018. CIE System for Metrology of Optical Radiation for ipRGCInfluenced Responses to Light. Vienna, Austria: International Commission on Illumination (CIE).

CIE (2018b). CIE 015:2018. Colorimetry, 4th Edition. Vienna, Austria: International Commission on Illumination (CIE).

Diakite, A. K., \& Knoop, M. (2019a). Data-driven spectral sky models: A review. Journal of the International Colour Association, 23, pp. 55-61.

Diakite, A. K., \& Knoop, M. (2019b). A data-driven colorimetric analysis of CIE Standard General Skies In: CIE x046: 2019 Proceedings of 29th CIE Session, Washington DC, USA, June 14-22, 2019. 
Diakite-Kortlever, A. K., \& Knoop, M. (2021). Forecast accuracy of existing luminance-related spectral sky models and their practical implications for the assessment of the non-imageforming effectiveness of daylight. Lighting Research and Technology, 0, pp. 1-20.

Dubnicka, R., Rusnak, A., Komar, L. Darula, S., \& Smola, A. (2014). Spectroradiometric analysis of sky types. According to CIE document CIE S 011/E:2003. In: CIEx039:2014 Proceedings of CIE 2014 „Lighting Quality and Energy Efficiency” Conference. pp. 708-715.

Elek, O., \& Kmoch, P. (2010). Real-time spectral scattering in large-scale natural participating media. In: Proceedings of the 26th Spring Conference on Computer Graphics.

Feister, U., \& Grewe, R. (1995). Spectral albedo measurements in the UV and visible region over different types of surfaces. Photochemistry and Photobiology, 62(4), pp. 736-744.

Haber, J., Magnor, M., \& Seidel, H.-P. (2005). Physically-based simulation of twilight phenomena. ACM Transactions on Graphics (TOG), 24(4), pp. 1353-1373.

Hernández-Andrés, J., Romero, J., \& Lee, R.L. (2001a). Colorimetric and spectroradiometric characteristics of narrow-field-of-view clear skylight in Granada, Spain. J. Opt. Soc. Am.A. 18(2), pp. 412-420.

Hernández-Andrés, J., Romero, J., Nieves, J.L., \& Lee, R.L. (2001b). Color and spectral analysis of daylight in southern Europe. J. Opt. Soc. Am. A, 18(6), pp. 1325-1335.

Hosek, L., \& Wilkie, A. (2012). An analytic model for full spectral sky-dome radiance. ACM Transactions on Graphics (TOG), 31(4), pp. 1-9.

Inanici, M., Brennan, M. \& Clark, E. (2015). Spectral daylighting simulations: Computing circadian light. In Proceedings of BS2015: 14th Conference of International Building Performance Simulation Association, Hyderabad, India, pp. 1245-1252.

Inanici, M. and L. ZGF Architects (2015). Lark spectral lighting.

https://faculty.washington.edu/inanici/Lark/Lark home page.html

Jakubiec, J. A., Van Den Wymelenberg, K., Inanici, M., \& Mahic, A. (2016, March). Accurate measurement of daylit interior scenes using high dynamic range photography. In Proceedings of the CIE 2016 Lighting Quality and Energy Efficiency Conference.

Jakubiec, J. A., Van Den Wymelenberg, K., Inanici, M., \& Mahic, A. (2016, July). Improving the accuracy of measurements in daylit interior scenes using high dynamic range photography. In Proceedings of the 32nd PLEA Conference, Los Angeles, CA, USA, pp. 1113.

Kider Jr, J. T., Knowlton, D., Newlin, J., Li, Y. K., \& Greenberg, D. P. (2014). A framework for the experimental comparison of solar and skydome illumination. ACM Transactions on Graphics (TOG), 33(6), pp. 1-12.

Knoop, M. (2014). Analysis of spatially resolved measurement approaches to assess spectral characteristics of sky patches. In: CIE x039:2014: Proceedings of CIE 2014 Lighting Quality \& Energy Efficiency, April 2014, Kuala Lumpur, Malaysia.

Knoop, M., Diakite, A., \& Rudawski, F. (2015). Methodology to create spectral sky models to enable the inclusion of colorimetric characteristics of daylight in research and design.

In Proceedings of CIE, Manchester, UK 
Knoop M., Abdelmageed A.A., Luo T., Weber N., \& Diakite A.K. (2017) Spatially resolved spectral sky daylight measurement data: Methods of collection, evaluation and representation. In: Proceedings of the CIE 2017 Midterm Meeting, Jeju (South Korea). pp. 1036-1046.

Knoop, M., Weber, N., Diakite, A.K. (2019) Approach to analyse seasonal and geographical variations in daylight illuminants In: CIE x046: 2019 Proceedings of 29th CIE Session, Washington DC, USA, June 14-22, 2019.

Kómar, L.; Rusnák, A., \& Dubnička, R. (2013). Analysis of diffuse irradiance from two parts of sky vault divided by solar meridian using portable spectral sky-scanner. Solar Energy. 96, pp. $1-9$.

Lucas, R. J., Peirson, S. N., Berson, D. M., Brown, T. M., Cooper, H. M., Czeisler, C. A., ... \& Price, L. L. (2014). Measuring and using light in the melanopsin age. Trends in neurosciences, 37(1), pp. 1-9.

Luo, T.; Lin. R.; Yan, D., \& Zhang, B. (2015). Measurement and study on the sky luminance and spectral distribution in Beijing. In: CIE 216:2015: Proceedings of the 28th Session of the CIE, 28 June - 4 July 2015, Manchester, United Kingdom.

Mayer, B., \& Kylling, A. (2005). The libRadtran software package for radiative transfer calculations-description and examples of use. Atmospheric Chemistry and Physics, 5(7), pp. 1855-1877.

Nayatani, Y., Wyszecki, G. (1963). Color of daylight from north sky. J. Opt. Soc. Am. 53(5), pp. 626-629.

Nishita, T., Dobashi, Y., \& Nakamae, E. (1996). Display of clouds taking into account multiple anisotropic scattering and sky light. In: Proceedings of the 23rd Annual Conference on Computer Graphics and Interactive Techniques.

Nishita, T., Sirai, T., Tadamura, K., \& Nakamae, E. (1993). Display of the earth taking into account atmospheric scattering. In: Proceedings of the 20th Annual Conference on Computer Graphics and Interactive Techniques.

Onagan, D. 2020. Analysis of Seasonal and Geographical Variations in Daylight Illuminants, MSc Thesis Technische Universität Berlin

O'Neil, S. (2005). Accurate Atmospheric Scattering. GPU Gems 2. In: Addison Wesley. Retrieved from https://developer.nvidia.com/gpugems/gpugems2/part-ii-shading-lighting-andshadows/chapter-16-accurate-atmospheric-scattering

Perez, R., Seals, R., \& Michalsky, J. (1993). All-weather model for sky luminance distribution-preliminary configuration and validation. Solar energy, 50(3), pp. 235-245.

Preetham, A. J., Shirley, P., \& Smits, B. (1999). A practical analytic model for daylight. In: Proceedings of the 26th Annual Conference on Computer Graphics and Interactive Techniques.

Rea, M. (2015). The lumen seen in a new light: Making distinctions between light, lighting and neuroscience. Lighting Research \& Technology, 47(3), pp. 259-280.

Rea, M. S., Figueiro, M. G., Bierman, A., \& Bullough, J. D. (2010). Circadian light. Journal of Circadian Rhythms, 8(1), pp. 1-10. 
Riechelmann, S., Schrempf, M., \& Seckmeyer, G. (2013). Simultaneous measurement of spectral sky radiance by a non-scanning multidirectional spectroradiometer

(MUDIS). Measurement Science and Technology, 24(12), 125501.

Ruppertsberg, A. I. and M. Bloj (2006). Rendering complex scenes for psychophysics using radiance: How accurate can you get? JOSA A 23(4), pp. 759- 768.

Rusnák A. Meranie a hodnotenie spektrálnych charakteristík slnečného žiarenia. (Measurements and evaluation of spectral sun radiation characteristics, Translation by Dr. Darula): PhD Dissertation. Slovenská Technická Univerzita v Bratislave, Bratislava, Slovenia; 2014.

Seckmeyer, G. Lagos Rivas, L., Gaetani, C., Heinzel, J.W., \& Schrempf, M. (2018).

Biologische und medizinische Wirkungen solarer Strahlung promet 100, pp. 117-128.

Shettle, E. (1989). Models of aerosols, clouds and precipitation for atmospheric propagation studies, In: Conference on Atmospheric Propagation in the UV, Visible, IR and MM-Region and Related System Aspects, NATO Adv. Group for Aerosp. Res. and Dev., Copenhagen.

Solemma (2017). ALFA Adaptive Lighting for Alertness. A new circadian lighting design software. [accessed 2020 Feb 2].

https://www.solemma.com/Alfa.html.

Spitschan, M., Aguirre, G. K., Brainard, D. H., \& Sweeney, A. M. (2016). Variation of outdoor illumination as a function of solar elevation and light pollution. Scientific reports, 6, 26756.

Takagi, A., Takaoka, H., Oshima, T., \& Ogata, Y. (1990). Accurate rendering technique based on colorimetric conception. ACM SIGGRAPH Computer Graphics, 24(4), pp. 263-272.

Tohsing, K.; Schrempf, M.; Riechelmann, S., \& Seckmeyer, G. (2014). Validation of spectral sky radiance derived from all-sky camera images-a case study. Atmospheric Measurement Techniques. 7(7), pp. 2137-2146.

Tregenza, P.R. (1987). Subdivision of the sky hemisphere for luminance measurements. Lighting Research \& Technology, 19(1), pp. 13-14.

Uetani, Y. 2014. Measurement of the all sky spectral radiance distribution using a fisheye camera and principal component analysis. In: Proceedings of EuroSun 2014, At Aix-lesBains, France.

Ward, G. J. (1994). The radiance lighting simulation and rendering system. In Proceedings of the 21st annual conference on Computer graphics and interactive techniques, pp. 459-472. ACM.

Ward, G.\& Eydelberg-Vileshin, E. (2002) Picture Perfect RGB Rendering Using Spectral Prefiltering and Sharp Color Primaries. In: 13th Eurographics Workshop on Rendering (EGWR02), Pisa, Italy, Eurographics Association, pp. 117-124.

Wyszecki, G. and W. S. Stiles (1982). Color science, Volume 8. Wiley New York. 


\section{Copyrights}

\begin{tabular}{|c|c|c|}
\hline Figure & Copyright by & License \\
\hline $\begin{array}{l}\text { Figure 1: Spectral sky scanner at daylight measuring site at the } \\
\text { Technische Universität Berlin }\end{array}$ & $\begin{array}{l}\text { Fachgebiet Lichttechnik TU } \\
\text { Berlin }\end{array}$ & CC BY 4.0 \\
\hline $\begin{array}{l}\text { Figure 2: AMUDIS at the measuring site of Leibniz Universität } \\
\text { Hannover }\end{array}$ & $\begin{array}{l}\text { Institut für Meteorologie und } \\
\text { Klimatologie, Leibniz } \\
\text { Universität Hannover }\end{array}$ & Copyright \\
\hline $\begin{array}{l}\text { Figure 3: Spectral sky scanner at measuring site of China } \\
\text { Academy of Building Research }\end{array}$ & $\begin{array}{l}\text { China Academy of Building } \\
\text { Research }\end{array}$ & Copyright \\
\hline $\begin{array}{l}\text { Figure 4: Image of in-situ measurements being collected in } \\
\text { Singapore }\end{array}$ & Priji Balakrishnan & CC-BY-NC \\
\hline $\begin{array}{l}\text { Figure 5: Comparison of three spectral sky measurements from } \\
\text { the Singapore dataset }\end{array}$ & $\begin{array}{l}\text { Priji Balakrishnan and Alstan } \\
\text { Jakubiec }\end{array}$ & CC-BY-NC \\
\hline $\begin{array}{l}\text { Figure 6: CIE x,y chromaticity diagram with the Planckian } \\
\text { Locus and daylight locus }\end{array}$ & $\begin{array}{l}\text { Fachgebiet Lichttechnik TU } \\
\text { Berlin }\end{array}$ & CC BY 4.0 \\
\hline $\begin{array}{l}\text { Figure 7: Examples of measurement points and local daylight } \\
\text { loci in a section of the CIE x,y chromaticity diagram (see Figure } \\
\text { 6) (Onagan 2020) }\end{array}$ & $\begin{array}{l}\text { Fachgebiet Lichttechnik TU } \\
\text { Berlin }\end{array}$ & CC BY 4.0 \\
\hline $\begin{array}{l}\text { Figure } 8 \text { (reproduced from Diakite and Knoop (2019a) with } \\
\text { permission from the publisher): Current state-of-the-art, data- } \\
\text { driven, spectral sky models based on the relationship between } \\
\text { luminance and correlated colour temperature (CCT) }\end{array}$ & $\begin{array}{l}\text { Fachgebiet Lichttechnik TU } \\
\text { Berlin }\end{array}$ & $\begin{array}{l}\text { Rights } \\
\text { reserved. } \\
\text { Used with } \\
\text { permission }\end{array}$ \\
\hline $\begin{array}{l}\text { Figure 9: Horizontal and zenith layers of the hemisphere } \\
\text { subdivision (cross section) }\end{array}$ & Stanislav Darula & Copyright \\
\hline $\begin{array}{l}\text { Figure 10: Scheme of proposed hemispherical sectors (plan } \\
\text { view) }\end{array}$ & Stanislav Darula & Copyright \\
\hline Figure 11: Fisheye picture overlayed by the sector mask & Stanislav Darula & Copyright \\
\hline $\begin{array}{l}\text { Figure 12: Location of } 145 \text { Tregenza point grid (dots) in } \\
\text { proposed segments }\end{array}$ & Stanislav Darula & Copyright \\
\hline $\begin{array}{l}\text { Figure 13: View of a double-glazing assembly's spectral } \\
\text { properties in Optics }\end{array}$ & Alstan Jakubiec & $\begin{array}{l}\text { CC BY- } \\
\text { NC-SA } 4.0\end{array}$ \\
\hline $\begin{array}{l}\text { Figure 14: Colour ranges indicated by black circles displayed in } \\
\text { the CIE } L^{*} a^{*} b^{*} \text { colour space }\end{array}$ & $\begin{array}{l}\text { Alstan Jakubiec } \\
\text { http://spectraldb.com/ }\end{array}$ & $\begin{array}{l}\text { CC BY- } \\
\text { NC-SA } 4.0\end{array}$ \\
\hline $\begin{array}{l}\text { Figure 15: Selected spectral reflectance distributions of similar } \\
\text { colors identified in Figure } 14\end{array}$ & Alstan Jakubiec & $\begin{array}{l}\text { CC BY- } \\
\text { NC-SA } 4.0\end{array}$ \\
\hline $\begin{array}{l}\text { Figure 16: Lark interface displaying step-by-step process of the } \\
\text { nine-channel calculation in three steps }\end{array}$ & Alstan Jakubiec & $\begin{array}{l}\text { CC BY- } \\
\text { NC-SA } 4.0\end{array}$ \\
\hline $\begin{array}{l}\text { Figure 17: Spectree process of modifying sky irradiance } \\
\text { contribution as } \\
\text { a function of ray-surface reflections and material properties }\end{array}$ & $\begin{array}{l}\text { Jon Sargent / Solemma } \\
\text { https://www.solemma.com/alfa }\end{array}$ & $\begin{array}{l}\text { Rights } \\
\text { reserved. } \\
\text { Used with } \\
\text { permission. }\end{array}$ \\
\hline $\begin{array}{l}\text { Figure 18: ALFA interface for displaying melanopic vertical } \\
\text { illuminance and hyperspectral renderings }\end{array}$ & Alstan Jakubiec & $\begin{array}{l}\text { CC BY- } \\
\text { NC-SA } 4.0\end{array}$ \\
\hline $\begin{array}{l}\text { Figure 19: Example of a momentary SDPD, reflecting the } \\
\text { momentary CCT on façades of any orientation (vertical) and } \\
\text { the horizontal plane, in comparison the D65 standard }(6500 \mathrm{~K}) \\
\text { under clear sky conditions (March } 17,2016)\end{array}$ & $\begin{array}{l}\text { Fachgebiet Lichttechnik TU } \\
\text { Berlin }\end{array}$ & CC BY 4.0 \\
\hline $\begin{array}{l}\text { Figure 20: Appearance of a residential building in Singapore } \\
\text { under different sky conditions. }\end{array}$ & Priji Balakrishnan & Copyright \\
\hline $\begin{array}{l}\text { Figure 21: Comparisons of the effects of direct light in HDR } \\
\text { photograph, non-spectral PEREZ render, spectral LARK and } \\
\text { ALFA renders of different urban environments under clear sky } \\
\text { conditions. }\end{array}$ & Priji Balakrishnan & $\begin{array}{l}\text { CC-BY- } \\
\text { NC-ND }\end{array}$ \\
\hline
\end{tabular}

